\title{
Parametric Optimization of Nd:YAG Laser Beam Machining Process Using Artificial Bee Colony Algorithm
}

\author{
Rajarshi Mukherjee, Debkalpa Goswami, and Shankar Chakraborty \\ Department of Production Engineering, Jadavpur University, Kolkata, West Bengal 700 032, India \\ Correspondence should be addressed to Shankar Chakraborty; s_chakraborty00@yahoo.co.in
}

Received 20 December 2012; Accepted 2 July 2013

Academic Editor: Josefa Mula

Copyright ( 2013 Rajarshi Mukherjee et al. This is an open access article distributed under the Creative Commons Attribution License, which permits unrestricted use, distribution, and reproduction in any medium, provided the original work is properly cited.

\begin{abstract}
Nd:YAG laser beam machining (LBM) process has a great potential to manufacture intricate shaped microproducts with its unique characteristics. In practical applications, such as drilling, grooving, cutting, or scribing, the optimal combination of Nd:YAG LBM process parameters needs to be sought out to provide the desired machining performance. Several mathematical techniques, like Taguchi method, desirability function, grey relational analysis, and genetic algorithm, have already been applied for parametric optimization of Nd:YAG LBM processes, but in most of the cases, suboptimal or near optimal solutions have been reached. This paper focuses on the application of artificial bee colony $(\mathrm{ABC})$ algorithm to determine the optimal Nd:YAG LBM process parameters while considering both single and multiobjective optimization of the responses. A comparative study with other populationbased algorithms, like genetic algorithm, particle swarm optimization, and ant colony optimization algorithm, proves the global applicability and acceptability of $\mathrm{ABC}$ algorithm for parametric optimization. In this algorithm, exchange of information amongst the onlooker bees minimizes the search iteration for the global optimal and avoids generation of suboptimal solutions. The results of two sample paired $t$-tests also demonstrate its superiority over the other optimization algorithms.
\end{abstract}

\section{Introduction}

Increasing demand for advanced difficult-to-machine materials and availability of high-power lasers have stimulated interest among the researchers for the development of laser beam machining (LBM) processes [1]. The LBM, which is a thermal energy-based machining process, is now being widely applied to fulfill the present day requirements of high flexibility and productivity, noncontact processing, elimination of finishing operations, adaptability to automation, reduced processing cost, improved product quality, greater material utilization, processing of materials irrespective of electrical conductivity, minimum heat affected zone (HAZ), and green manufacturing. In this process, the material is removed by (a) melting, (b) vaporization, and (c) chemical degradation where the chemical bonds are broken causing the materials to degrade. When a high energy density laser beam is focused on a work surface, the thermal energy is absorbed which heats and transforms the work volume into a molten, vaporized, or chemically changed state that can easily be removed by the flow of high pressure assist gas jet. This process also does not involve any mechanical cutting force and tool wear. Using LBM method, several material processing operations, such as laser microdrilling, cutting, microgrooving, microturning, marking, or scribing can be done $[2,3]$.

Among various types of lasers used for machining in industries, $\mathrm{CO}_{2}$ and Nd:YAG lasers are the most established. Although $\mathrm{CO}_{2}$ lasers have wide application in commercial sheet metal cutting operations, the benefits offered by $\mathrm{Nd}$ :YAG laser make it an interesting field of investigation. Experimental results show that Nd:YAG laser has some unique characteristics. Although the mean beam power is relatively low, the beam intensity can be relatively high due to smaller pulse duration and better focusing behavior. Smaller kerf width, microsize holes, narrower HAZ, and better cut edge kerf profile can be obtained in Nd:YAG LBM process. The smaller thermal load offered by Nd:YAG laser allows the machining of some brittle materials, such as $\mathrm{SiC}$ ceramics, 
which cannot be machined by $\mathrm{CO}_{2}$ laser without crack damage.

As Nd:YAG LBM is a complex dynamic process with numerous parameters, like lamp current, pulse frequency, air pressure, pulse width, and cutting speed, so in order to maintain a high production rate and an acceptable level of quality for the machined parts, it is important to select the optimal combination of the process parameters, because these parameters directly affect the physical characteristics of the machined parts, as signified by kerf width, HAZ thickness, taper, and surface roughness. Experimental and theoretical studies show that the performance of Nd:YAG LBM process can be significantly improved by proper selection of the machining parameters [4]. For this purpose, the process engineers have to often rely on the manufacturer's data or handbook data. Hence, there is an ardent need for some sound optimization tools to determine the optimal machining parameters for Nd:YAG LBM process to have enhanced performance.

Mathew et al. [5] developed predictive models based on some important process parameters to determine the optimal process parameter ranges for pulsed Nd:YAG laser machining operation on carbon fibre reinforced plastic composites. Using response surface methodology (RSM), Kuar et al. [6] performed parametric analysis to determine the optimal setting of process parameters, like pulse frequency, pulse width, lamp current, and assist air pressure, for achieving minimum HAZ thickness and taper of microholes machined on zirconium oxide $\left(\mathrm{ZrO}_{2}\right)$ by pulsed Nd:YAG laser. Kuar et al. [7] studied the effects of several laser machining parameters on HAZ thickness and taper of the microdrilled holes on alumina-aluminium composites using RSM technique. Dhupal et al. [8] considered lamp current, pulse frequency, pulse width, assist air pressure, and cutting speed as the machining parameters during pulsed Nd:YAG laser microgrooving operation and developed RSM-based equations to study the effects of those parameters on upper width, lower width, and depth of trapezoidal microgrooves. The optimal parametric combination was validated through experimentation and artificial-neural-network-(ANN-) based predictive model. Dubey and Yadava [9] presented a hybrid Taguchi method and RSM technique for simultaneous optimization of kerf width and material removal rate (MRR) for a laser beam cutting process. Dhupal et al. [10] investigated the effects of lamp current, pulse frequency, pulse width, assist air pressure, and cutting speed of workpiece on upper deviation, lower deviation, and depth characteristics of laser-turned microgrooves produced on cylindrical $\mathrm{Al}_{2} \mathrm{O}_{3}$ workpiece. Dubey and Yadava [11] simultaneously optimized kerf deviation and kerf width using Taguchi quality loss function during pulsed Nd:YAG laser beam cutting of aluminium alloy sheet. Dhupal et al. [12] developed RSM-based mathematical models and analyzed the machining characteristics of pulsed Nd:YAG laser during micro-grooving operation on aluminum titanate workpiece. Çaydaş and Hasçalık [13] presented a grey relational analysis-based approach for optimization of laser cutting process of St-37 steel with multiple performance characteristics. Dhupal et al. [14] selected lamp current, pulse frequency, pulse width, cutting speed, and assist gas pressure as the major machining parameters for producing square micro-grooves on cylindrical surface. A predictive model for laser turning process parameters was developed using a feedforward ANN technique, and an optimization problem was constructed based on RSM and then solved using genetic algorithm. Rao and Yadava [15] proposed a hybrid optimization approach for determining the optimal laser cutting process parameters to minimize kerf width, kerf taper, and kerf deviation together during pulsed Nd:YAG laser cutting of a thin sheet of nickel-based superalloy. Ciurana et al. [16] modeled the relationship between laser micromachining process parameters and quality characteristics using ANN and carried out multi-objective particle swarm optimization of the process parameters for minimum surface roughness and volume error. Based on RSM technique, Sivarao et al. [17] studied the effects of cutting speed, frequency, and duty cycle on surface roughness in the laser cutting process of mild steel. Doloi et al. [18] developed RSM-based mathematical models and analyzed the machining characteristics of pulsed Nd:YAG laser during micro-grooving operation on flat surface of aluminium titanate in order to optimize the parametric setting for achieving accurate taper angles of micro-grooves. Kuar et al. [19] performed RSM-based parametric analysis to investigate the change in the responses with the input parameters, such as pulse frequency, pulse width, lamp current, and assist air pressure, for achieving minimum height of the recast layer and maximum depth of the microgroove. Sharma et al. [20] performed parametric optimization of the kerf quality characteristics (kerf width, kerf taper, and kerf deviation) during pulsed Nd:YAG laser cutting of nickel-based superalloy thin sheet. Biswas et al. [21] investigated the effects of different process parameters on hole circularity at exit and taper of the hole during Nd:YAG laser microdrilling on gamma-titanium aluminide. Kibria et al. [22] performed experimental analysis on Nd:YAG laser microturning of cylindrical-shaped ceramic materials to achieve the desired responses, that is, depth of cut and surface roughness while varying the laser micro-turning process parameters, such as lamp current, pulse frequency, and laser beam scanning speed. Biswas et al. [23] observed the effects of five parameters on circularity and taper of holes in pulsed Nd:YAG laser microdrilling process and concluded that the circularity of the drilled hole at entry, exit, and taper were the important attributes influencing the quality of the hole. Biswas et al. [24] investigated the effects of lamp current, pulse frequency, pulse width, air pressure, and focal length of Nd:YAG laser micro-drilling process on hole circularity at entry and exit using RSM-based experimental results. Panda et al. [25] applied grey relational approach for determining the optimal process parameters to minimize HAZ and hole circularity and maximize MRR in pulsed Nd:YAG laser micro-drilling on high carbon steel. Sibalija et al. [26] presented a hybrid design strategy for determining the optimal laser drilling parameters in order to simultaneously meet all the requirements for seven quality characteristics of the holes produced during pulsed Nd:YAG laser drilling on a thin sheet of nickel-based superalloy.

Although the earlier researchers have applied different optimization techniques, like Taguchi method, grey relational 
analysis, desirability function, and genetic algorithm, for finding out the optimal process parameter values, in most of the cases, suboptimal or near optimal solutions have been reached In this paper, the application of artificial bee colony $(A B C)$ algorithm is validated as an effective and efficient tool for parametric optimization of Nd:YAG LBM process. The optimization performance of $\mathrm{ABC}$ algorithm is also compared with that of other population-based algorithms, like genetic algorithm (GA), particle swarm optimization (PSO), and ant colony optimization (ACO) which proves the superiority of $\mathrm{ABC}$ algorithm.

\section{Artificial Bee Colony Algorithm}

Artificial bee colony algorithm is an evolutionary computational technique, developed by Karaboga et al. [27-30]. In this algorithm, the colony of artificial bees consists of three groups, that is, employed bees, onlookers, and scouts. The first half of the colony consists of the employed artificial bees and the second half includes the onlookers. For every food source, there is only one employed bee. Thus, the number of employed bees is equal to the number of food sources around the hive. The employed bee whose food source has been abandoned becomes a scout.

In this algorithm, the position of a food source represents a possible solution to the considered optimization problem and the nectar amount of the food source is proportional to the quality or fitness of the associated solution. The number of the employed bees or onlooker bees is equal to the number of solutions in the population. In the first step, the $A B C$ algorithm generates randomly distributed predefined number of initial population, $P$, (position of the food sources) of SN populations, where $P \in \mathrm{SN}$. Each position of the food source, $x_{i j k}$, is three-dimensional with $i=1,2, \ldots, \mathrm{SN} ; j=$ $1,2, \ldots, D ; k=1,2, \ldots, V$, where $D$ is the dimension of each variable and $V$ is the number of variables in the objective function. After initialization, the population of the positions (solutions) is subjected to repeated cycles, $C=1,2, \ldots, \mathrm{MCN}$ (maximum cycle number) of the search processes of the employed, onlooker, and scout bees.

An employed bee produces a modification on the position (solution) in its memory depending on the local information (visual information) and tests the nectar amount (fitness value) of the new food source (new solution). Provided that the nectar amount of the new source is higher than that of the previous one, the bee memorizes the new position and forgets the old one. Otherwise, it keeps the position of the previous source in its memory. When all the employed bees complete the search process, they share the nectar information of the food sources and their position information with the onlooker bees in the dance area. An onlooker bee evaluates the nectar information taken from all the employed bees and selects a food source with a probability related to its nectar amount. As in the case of an employed bee, the onlooker bee produces a modification on the position in its memory and checks the nectar amount of the candidate source. If its nectar amount is higher than that of the previous one, the onlooker bee memorizes the new position and forgets the old one.
An artificial onlooker bee selects a food source depending on the probability value associated with that food source, $p_{i}$, as given in the following equation:

$$
p_{i}=\frac{\text { fit }_{i}}{\sum_{i=1}^{\mathrm{SN}} \mathrm{fit}_{i}},
$$

where $\mathrm{fit}_{i}$ is the fitness value of $i$ th solution which is proportional to the nectar amount of the food source in $i$ th position and $\mathrm{SN}$ is the number of food sources which is equal to the number of employed bees.

In order to produce a candidate food position from the old one in memory, the $\mathrm{ABC}$ algorithm adopts the following expression:

$$
v_{i j k}=x_{i j k}+\varphi\left(x_{i j k}-x_{l j k}\right),
$$

where $v_{i j k}$ is the candidate food position. Although $l$ is determined randomly, it has to be different from $i \cdot \varphi$ is a random number between -1 and 1 . It controls the production of the neighborhood food sources around $x_{i j}$ and represents the visual comparison of two food positions by a bee. From (2), it can be seen that as the difference between the parameters of $x_{i j k}$ and $x_{l j k}$ decreases, the perturbation on the position $x_{i j k}$ gets decreased too. Thus, as the search process approaches to the optimal solution in the search space, the step length is adaptively reduced. If a parameter value produced by this operation exceeds its predetermined limit, the parameter can be set to an acceptable value. Here, the value of the parameter exceeding its limit is set to its limit value.

The food source of which the nectar is abandoned by the bees is replaced with a new food source by the scouts. In $\mathrm{ABC}$ algorithm, this is simulated by producing a random position and replacing it with the abandoned one. In this algorithm, providing that a position (solution) cannot be improved further through a predetermined number of cycles, then that food source is assumed to be abandoned. The value of the predetermined number of cycles is an important control parameter of $\mathrm{ABC}$ algorithm, which is known as "limit" for abandonment. Assume that the abandoned source is $x_{i}$ and $j \in\{1,2,3, \ldots, D\}, k \in\{1,2,3, \ldots, V\}$, then the scout discovers a new food source to be replaced with $x_{i}$. This operation can be defined using the following equation:

$$
x_{i j k}=x_{\min j k}+\operatorname{rand}(0,1)\left(x_{\max j k}-x_{\min j k}\right),
$$

where $x_{\max j k}$ and $x_{\min j k}$ are the upper and lower bounds of $k$ th variable, respectively. At each candidate source position, the value of $v_{i j k}$ is searched out and evaluated by the artificial bees. Its performance is then compared with that of the old one. If the new food source has equal or better nectar amount than the old one, it is replaced with the old one in the memory. Otherwise, the old food source is retained in the memory. In other words, a greedy selection mechanism is employed as the selection process between the old and the candidate one. The main steps of $\mathrm{ABC}$ algorithm are given below [27].

(i) Initialize.

(ii) Repeat. 
(a) Place the employed bees on the food sources in the memory.

(b) Place the onlooker bees on the food sources in the memory.

(c) Send the scouts to the search area for discovering new food sources.

(iii) Until (all the requirements are met).

The detailed pseudocode of $\mathrm{ABC}$ algorithm is presented as follows [31]:

(1) Initialize the population of solutions $x_{i j k}(i=$ $1,2, \ldots, \mathrm{SN} ; j=1,2, \ldots, D ; k=1,2, \ldots, V)$.

(2) Evaluate the population.

(3) Cycle $=1$.

(4) Repeat.

(5) Produce new solutions $v_{i j k}$ for the employed bees and evaluate them.

(6) Apply the greedy selection process.

(7) Calculate the probability values for the solutions $x_{i j k}$.

(8) Produce the new solutions $v_{i j k}$ for the onlookers from the solutions $x_{i j k}$ selected depending on probability values and evaluate them.

(9) Apply the greedy selection process.

(10) Determine the abandoned solution for the scout, if exists, and replace it with a new randomly produced solution $x_{i j k}$.

(11) Memorize the best solution achieved so far.

(12) Cycle $=$ cycle +1 .

(13) Until cycle $=$ MCN.

\section{Optimization of Nd:YAG LBM Processes}

In order to validate the applicability and performance of ABC algorithm for parametric optimization of Nd:YAG LBM process, the experimental data and mathematical modeling of two LBM processes $[6,10]$ are analyzed here. For each of these processes, both the single and multi-objective optimizations of the responses are performed. For application of $\mathrm{ABC}$ algorithm, a computer code is developed in MATLAB 7.6 (R2008a) with the following control parameters: swarm size $=10$, number of employed bees $=50 \%$ of the swarm size, number of onlookers $=50 \%$ of the swarm size, number of scouts per cycle $=1$, number of cycles $=2000$, and runtime $=2$.

The role of various control parameters in ABC algorithm is also quite important, which mainly drive the operational aspect of this algorithm. For example, swarm size, number of employed bees, and number of onlookers directly influence selection of the initial starting point for this algorithm and control the number of bees participating in the search process (in this case, beginning of simultaneous search conditions initiated by each bee). Also, the number of onlookers directly
TABLE 1: Machining parameters with their levels.

\begin{tabular}{lccccc}
\hline \multirow{2}{*}{ Parameter } & \multicolumn{5}{c}{ Levels } \\
& -2 & -1 & 0 & 1 & 2 \\
\hline Lamp current $\left(x_{1}\right)(\mathrm{amp})$ & 17 & 19 & 21 & 23 & 25 \\
Pulse frequency $\left(x_{2}\right)(\mathrm{kHz})$ & 1 & 2 & 3 & 4 & 5 \\
Air pressure $\left(x_{3}\right)\left(\mathrm{kg} / \mathrm{cm}^{2}\right)$ & 0.6 & 1 & 1.4 & 1.8 & 2.2 \\
Pulse width $\left(x_{4}\right)(\%)$ & 2 & 6 & 10 & 14 & 18 \\
\hline
\end{tabular}

influences how quickly the potential food sources are evaluated: higher number of onlooker bees means quick collection of information from the employed bees and thus selection or rejection of food sources will be faster. Similarly, number of scouts per cycle will quicken the search process for new food source in every cycle. Finally, the number of cycles represents how many times the algorithm will be run before termination and may prove to be useful where there are a large number of variables to be evaluated.

Changing the values of various control parameters in $\mathrm{ABC}$ algorithm may increase/decrease the number of iterations to reach the optimal solution, but there will not be any significant change in the optimal solution. In this paper, the control parameters are selected based on the nature of the mathematical model (second-order equations with four/five variables) and capacity of CPU used $(1.83 \mathrm{GHz}$ Core $2 \mathrm{DUO}$ processor with $1 \mathrm{~GB}$ RAM): high end CPU may run with higher number of cycles and higher number of swarm size, but for CPU with limited resource, higher values of control parameters may cause CPU to freeze and RAM to overflow.

3.1. Example 1. Kuar et al. [6] performed laser beam microdrilling operation on zirconia $\left(\mathrm{ZrO}_{2}\right)$ ceramics of size $20 \times$ $20 \mathrm{~mm}$ and $1 \mathrm{~mm}$ thick and studied the influences of four process parameters, that is, lamp current, pulse frequency, air pressure, and pulse width on HAZ thickness and taper of the drilled holes. Each of those four process parameters was set at five different levels, as given in Table 1.

To determine the multiparametric optimal combinations for pulsed Nd:YAG laser beam microdrilling process on $\mathrm{ZrO}_{2}$ ceramics, experiments were carried out according to a central composite rotatable second-order design plan based on RSM technique and the following two equations were developed for HAZ thickness and taper:

$$
\begin{aligned}
Y_{u}(\mathrm{HAZ})= & 0.3796+0.07888 x_{1}-0.04120 x_{2} \\
& -0.04301 x_{3}-0.00570 x_{4}+0.02146 x_{1}^{2} \\
& -0.00957 x_{2}^{2}+0.00266 x_{3}^{2}-0.01234 x_{4}^{2} \\
& -0.0228 x_{1} x_{2}-0.00679 x_{1} x_{3}-0.03158 x_{1} x_{4} \\
& +0.01341 x_{2} x_{3}-0.00983 x_{2} x_{4}-0.00497 x_{3} x_{4}, \\
Y_{u}(\text { Taper })= & 0.07253+0.00912 x_{1}+0.00887 x_{2} \\
& -0.00606 x_{3}+0.00449 x_{4}+0.00153 x_{1}^{2} \\
& +0.00225 x_{2}^{2}+0.00233 x_{3}^{2}+0.00399 x_{4}^{2} \\
& +0.00431 x_{1} x_{2}-0.00646 x_{1} x_{3}-0.00519 x_{1} x_{4} \\
& -0.00110 x_{2} x_{3}-0.00023 x_{2} x_{4}-0.07253 x_{3} x_{4} .
\end{aligned}
$$


TABLE 2: Results for single objective optimization.

\begin{tabular}{|c|c|c|c|c|c|c|}
\hline Optimization method & Response & Optimal value & Lamp current (amp) & Pulse frequency $(\mathrm{kHz})$ & Air pressure $\left(\mathrm{kg} / \mathrm{cm}^{2}\right)$ & Pulse width (\%) \\
\hline \multirow{2}{*}{ Kuar et al. [6] } & HAZ & 0.0675 & 17 & 2 & 2 & 2 \\
\hline & Taper & 0.0319 & 17 & 2 & 0.6 & 2 \\
\hline \multirow{2}{*}{ GA } & HAZ & 0.1066 & 19 & 1 & 2 & 2 \\
\hline & Taper & 0.0843 & 23.86 & 2.29 & 1.38 & 13.92 \\
\hline \multirow{2}{*}{ PSO algorithm } & HAZ & 0.0604 & 18 & 1.25 & 2.12 & 2.4 \\
\hline & Taper & 0.0458 & 20.23 & 4.10 & 1.81 & 11.95 \\
\hline \multirow{2}{*}{ ACO algorithm } & HAZ & 0.0324 & 17 & 1.5 & 2 & 2 \\
\hline & Taper & 0.0377 & 18.04 & 4.47 & 1.73 & 14.18 \\
\hline \multirow{2}{*}{$\mathrm{ABC}$ algorithm } & HAZ & 0.0174 & 17.0 & 4.8 & 2.1 & 2 \\
\hline & Taper & 0.0202 & 18.2 & 1.25 & 0.6 & 2 \\
\hline
\end{tabular}

TABLE 3: Single objective optimization performance.

\begin{tabular}{lccccc}
\hline Optimization method & Response & Optimal value & Mean & Standard deviation & Standard error \\
\hline \multirow{2}{*}{ GA } & HAZ & 0.1066 & 0.1231 & 0.0102 & 0.0032 \\
& Taper & 0.0843 & 0.1056 & 0.0151 & 0.0047 \\
\hline \multirow{2}{*}{ PSO algorithm } & HAZ & 0.0604 & 0.0883 & 0.0212 & 0.0138 \\
& Taper & 0.0458 & 0.0662 & 0.0129 & 0.0043 \\
\hline \multirow{2}{*}{ ACO algorithm } & HAZ & 0.0324 & 0.0505 & 0.0098 & 0.0041 \\
& Taper & 0.0377 & 0.0507 & 0.0094 & 0.0031 \\
\multirow{2}{*}{ ABC algorithm } & HAZ & 0.0174 & 0.0301 & 0.0092 & 0.0030 \\
& Taper & 0.0202 & 0.0346 & 0.0029 \\
\hline
\end{tabular}

3.1.1. Single Objective Optimization. In this case, the secondorder RSM-based equations for the two responses are optimized separately. Here, both the responses are to be minimized with respect to the constraints set as $17 \leq x_{1} \leq$ $25,1 \leq x_{2} \leq 5,0.6 \leq x_{3} \leq 2.2$, and $2 \leq x_{4} \leq 18$. Kuar et al. [6] obtained the optimal settings of lamp current = $17 \mathrm{amp}$, pulse frequency $=2 \mathrm{kHz}$, air pressure $=2 \mathrm{~kg} / \mathrm{cm}^{2}$ and pulse width $=2 \%$; lamp current $=17 \mathrm{amp}$, pulse frequency $=2 \mathrm{kHz}$, air pressure $=0.6 \mathrm{~kg} / \mathrm{cm}^{2}$, and pulse width $=2 \%$ for minimum values of HAZ thickness of $0.0675 \mathrm{~mm}$ and taper of $0.0319 \mathrm{~mm}$, respectively. These optimal parametric settings are shown in Table 2. This table also shows the results when $\mathrm{ABC}$ algorithm is applied to optimize these two RSM-based equations with respect to the given constraints. It is observed that while employing $\mathrm{ABC}$ algorithm, the minimum value of HAZ thickness is drastically reduced from 0.0675 to $0.0174 \mathrm{~mm}$ and the minimum taper is also decreased from 0.0319 to $0.0202 \mathrm{~mm}$. The optimal process settings are also changed. The optimization results for GA, PSO, and ACO algorithms are also given in Table 2, which proves the superiority of $\mathrm{ABC}$ algorithm over the others with respect to their optimization performance. Figure 1 shows the convergence diagram for all the considered optimization techniques for HAZ thickness. The termination criterion for each algorithm is set at 500 iterations; that is, after 500 iterations, the algorithm will be terminated and all the 500 solutions will be plotted on the convergence diagram. The best value is taken as the optimal solution of the objective function obtained by the algorithm. From Figure 1, it is clear that $\mathrm{ABC}$ algorithm outperforms the other populationbased algorithms while achieving the minimum value of HAZ thickness.

In order to study the optimization performance of $\mathrm{ABC}$, ACO, PSO, and GA algorithms in details, the mean, standard deviation, and standard error of the obtained optimal values are computed, as given in Table 3 . It is noted that the optimization performance of $\mathrm{ABC}$ algorithm is better than that of ACO, PSO, and GA with respect to the dispersion of the optimal solution values. The results of two sample paired $t$-tests, as exhibited in Table 4, show that the differences in optimization performance between $\mathrm{ABC}$ algorithm and other considered population-based algorithms are statistically significant at $5 \%$ significance level. It is also observed that the optimization performance of $\mathrm{ABC}$ algorithm is relatively more consistent than that of other algorithms. Table 5 compares the required computational (CPU) times for all the considered algorithms when run in an Intel Core 2 DUO, $1.83 \mathrm{GHz}, 1 \mathrm{~GB}$ RAM CPU computer platform. It is interesting to note that although $\mathrm{ABC}$ algorithm has excellent optimization performance, its CPU time is not so very high compared to the other algorithms under consideration. Hence, it can be an effective optimization tool for finding out the best parametric combination of Nd:YAG LBM process for its enhanced machining performance.

Figure 2 shows the variations of HAZ thickness with respect to the four LBM process parameters. It is observed that with the increase in lamp current and pulse width, HAZ thickness increases, whereas it decreases with increasing 
TABLE 4: Two sample paired $t$-tests between different algorithms.

\begin{tabular}{|c|c|c|}
\hline Optimization methods & Response & Results of paired $t$-test \\
\hline \multirow[t]{2}{*}{ GA versus $A B C$ algorithm } & HAZ & $\begin{array}{l}\text { 95\% CI for mean difference: }(0.08886,0.09616), t \text {-test of mean difference }=0 \text { (versus } \\
\text { not }=0), t \text { value }=50.97, P \text { value }=0.000\end{array}$ \\
\hline & Taper & $\begin{array}{l}95 \% \text { CI for mean difference: }(0.06522,0.07526), t \text {-test of mean difference }=0 \text { (versus } \\
\text { not }=0), t \text { value }=28.13, P \text { value }=0.000\end{array}$ \\
\hline \multirow[t]{2}{*}{ PSO algorithm versus $\mathrm{ABC}$ algorithm } & HAZ & $\begin{array}{l}\text { 95\% CI for mean difference: }(0.05068,0.06520), t \text {-test of mean difference }=0 \\
\text { (versus not }=0), t \text { value }=16.05, P \text { value }=0.000\end{array}$ \\
\hline & Taper & $\begin{array}{l}95 \% \text { CI for mean difference: }(0.02703,0.03450), t \text {-test of mean difference }=0 \\
\text { (versus not }=0), t \text { value }=16.55, P \text { value }=0.000\end{array}$ \\
\hline \multirow[t]{2}{*}{$\mathrm{ACO}$ algorithm versus $\mathrm{ABC}$ algorithm } & HAZ & $\begin{array}{l}95 \% \text { CI for mean difference: }(0.01633,0.02440), t \text {-test of mean difference }=0 \text { (versus } \\
\text { not }=0), t \text { value }=10.13, P \text { value }=0.000\end{array}$ \\
\hline & Taper & $\begin{array}{l}95 \% \text { CI for mean difference: }(0.01000,0.01835), t \text {-test of mean difference }=0 \text { (versus } \\
\text { not }=0), t \text { value }=6.82, P \text { value }=0.000\end{array}$ \\
\hline
\end{tabular}

TABle 5: CPU time for ABC, ACO, PSO, and GA algorithms.

\begin{tabular}{lc}
\hline Optimization method & Average CPU time (in sec) \\
\hline ABC algorithm & 13.8 \\
ACO algorithm & 13.6 \\
PSO algorithm & 14.1 \\
GA & 13.4 \\
\hline
\end{tabular}

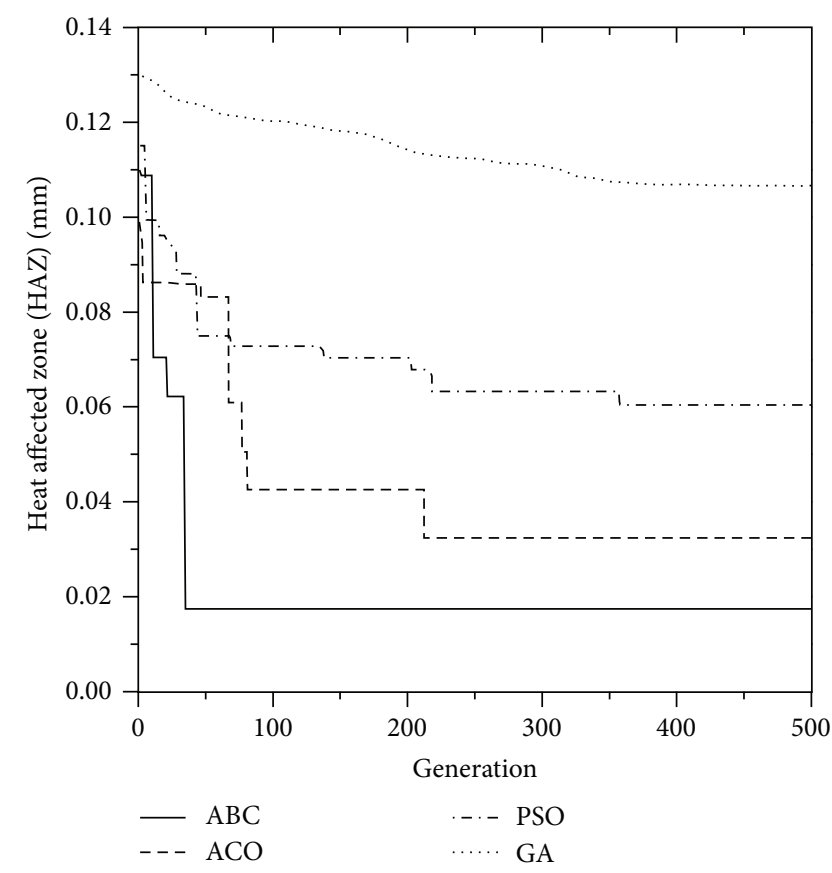

FIgURE 1: Convergence of ABC, ACO, PSO, and GA algorithms for HAZ thickness.

values of pulse frequency and assist air pressure. The energy of a laser beam is directly proportional to lamp current. High lamp current generates high thermal energy, which produces high HAZ thickness. At low pulse frequency, peak power of the laser beam is higher causing excessive material removal. But at higher pulse frequency as the peak power of laser beam is less, HAZ thickness is comparatively lower. It has also been found that the assist air pressure has an almost linear relationship with HAZ thickness [6]. Low assist air pressure is unable to remove the excess heat generated at the micro-drilling zone as well as being unable to assist the removal of ejected material. This phenomenon causes high HAZ thickness. However, at higher assist air pressure, the excess amount of heat can be rapidly removed which also helps in ejecting the molten material. As a result, low HAZ thickness can be observed. At lower pulse width, highly concentrated laser beam can easily penetrate into the material causing less HAZ thickness. Then HAZ thickness rapidly increases due to surface deposition of the molten material.

During pulsed Nd:YAG laser micro-drilling operation, minimization of taper of the micro-hole is highly required for maintaining quality and accuracy of the hole. Kuar et al. [6] observed that taper increases significantly with lamp current. High lamp current generates high thermal energy, and as a result, the top surface of work sample where the laser beam is focused gets melted and vaporized instantly, and large volume of material is removed from the top surface, which produces large taper. At very high pulse frequency, relatively large taper is observed, but at low pulse frequency, low taper is generated. At very low pulse frequency, the beam energy is slightly high but the time between two successive incident beams is more; therefore, material is removed only from the narrow focusing spot on the top surface of work sample. It has been observed that taper is significantly increased with the increase in assist air pressure [6]. Zirconia has a very low thermal conductivity and the higher assist air pressure cools the localized heating zone causing slower rate of material removal to penetrate up to the whole thickness of the work sample. As a result, laser beam energy for longer period causes large area material removal from the top surface of the hole, resulting in an increase in taper with increasing assist air pressure. At low pulse width, highly concentrated laser beam energy causes faster rate of penetration, and as a result less taper is formed. These same observations are also obtained in Figure 3 where the variations of taper with respect to four LBM process parameters are exhibited.

3.1.2. Multiobjective Optimization. In multi-objective optimization of Nd:YAG LBM process, instead of treating the 


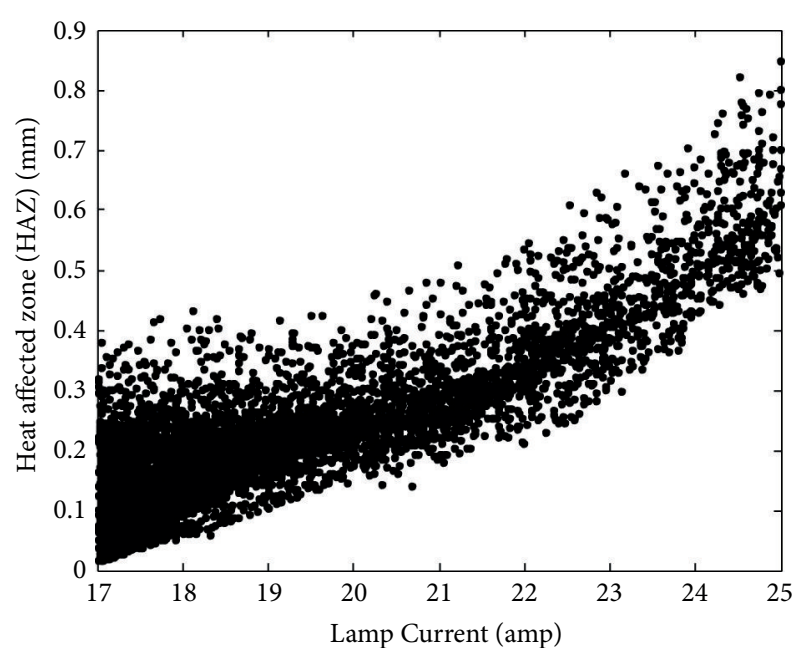

(a)

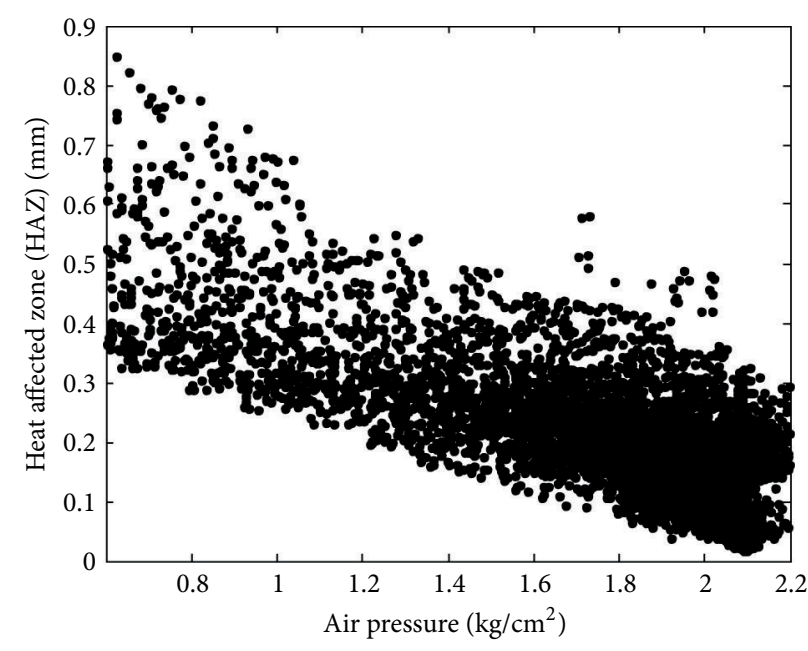

(c)

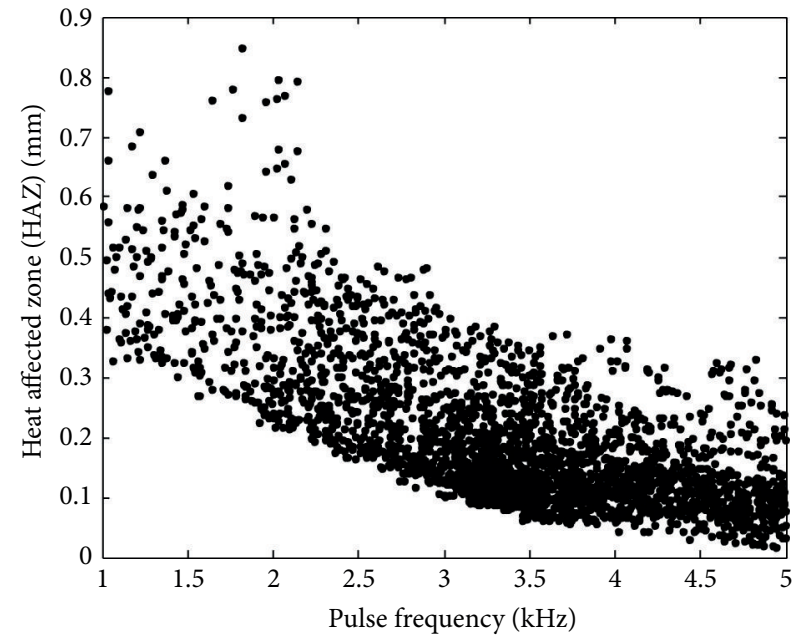

(b)

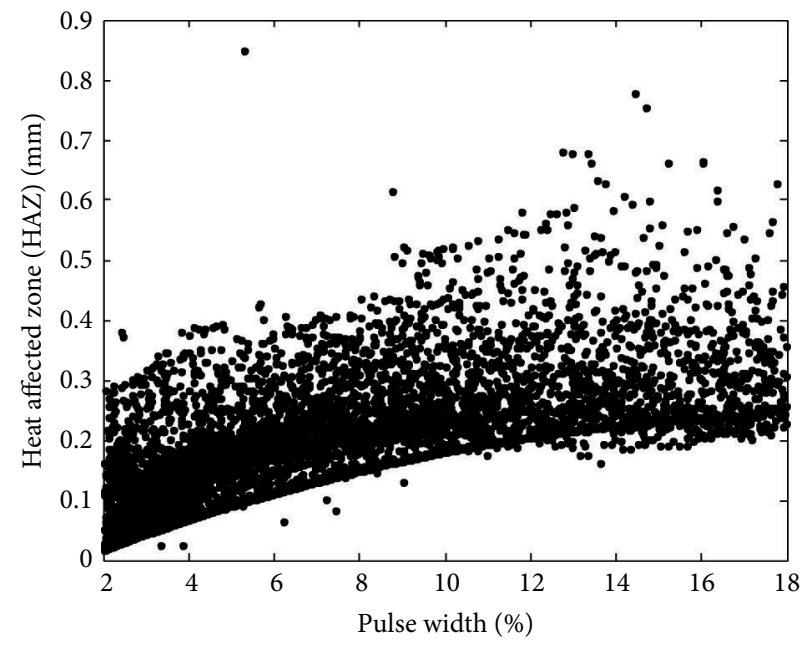

(d)

FIGURE 2: Variations of HAZ thickness with LBM process parameters.

two responses separately, both are simultaneously optimized, based on the following objective function [31]:

$$
\operatorname{Min}\left(Z_{1}\right)=\frac{w_{1} Y_{u}(\mathrm{HAZ})}{\mathrm{HAZ}_{\min }}+\frac{w_{2} Y_{u}(\text { Taper })}{\text { Taper }_{\min }},
$$

where $Y_{u}(\mathrm{HAZ})$ and $Y_{u}$ (Taper) are the second-order RSMbased equations for HAZ thickness and taper, respectively; $\mathrm{HAZ}_{\text {min }}$ and $\mathrm{Taper}_{\text {min }}$ are the minimum values of HAZ thickness and taper, respectively; $w_{1}$ and $w_{2}$ are the weights or priority values assigned to HAZ thickness and taper, respectively. These weights can be anything such that $w_{1}+$ $w_{2}=1$. Assignment of the weights (relative importance) to different responses is entirely based on the knowledge and experience of the concerned process engineers. Sometimes, analytic hierarchy process [32] is employed to determine these weight values. The $\mathrm{HAZ}_{\min }$ and $\mathrm{Taper}_{\min }$ values are obtained from the single objective optimization results. Here, equal weights for both the responses, that is, $w_{1}=w_{2}=$ 0.5 , (case 1) are first considered and the results obtained after solving this multi-objective optimization problem using $\mathrm{ABC}$ algorithm are given in Table 6. The constraints for this multi-objective optimization problem are the same as set for single objective optimization. The minimum HAZ thickness and taper values are obtained as $0.1019 \mathrm{~mm}$ and $0.0248 \mathrm{~mm}$, respectively, which are quite better than those observed by Kuar et al. [6]. The optimal solution $\left(Z_{1}\right)$ is 0.0634 . Table 6 also shows the results of multi-objective optimization where two other weighting schemes to the responses (case 2: $w_{1}$ $=0.9$ and $w_{2}=0.1$, and case 3: $w_{1}=0.1$ and $w_{2}=0.9$ ) are considered. In case 2, maximum weight is assigned to HAZ thickness and in case 3 , minimization of taper is given more importance. In both these cases, the optimal process settings are changed. Table 7 gives a comparative analysis of the multiobjective optimization performance of $\mathrm{ABC}$ algorithm for all the three cases and it is important to note that the best performance is achieved when equal importance is given to the responses. Thus, based on these optimization results, it is always recommended to assign equal weights to all the responses. 


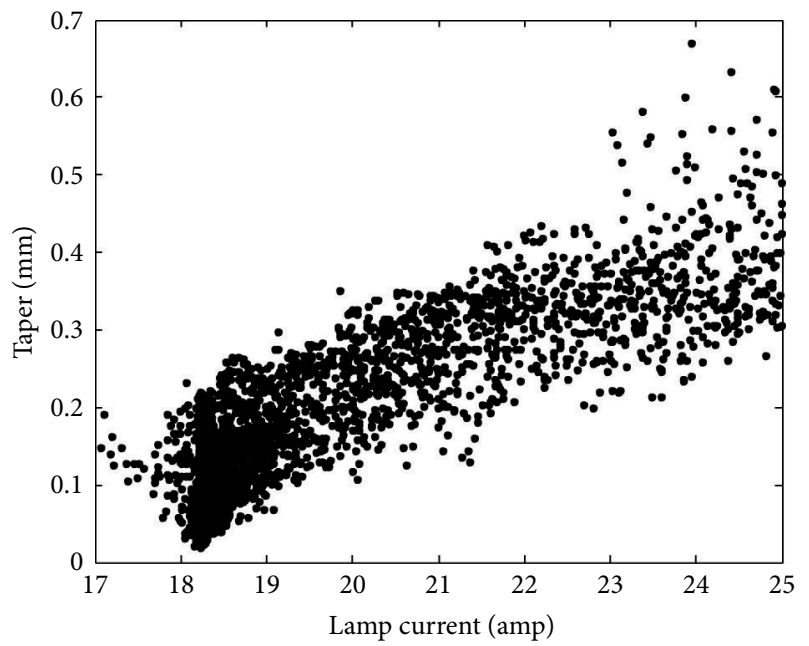

(a)

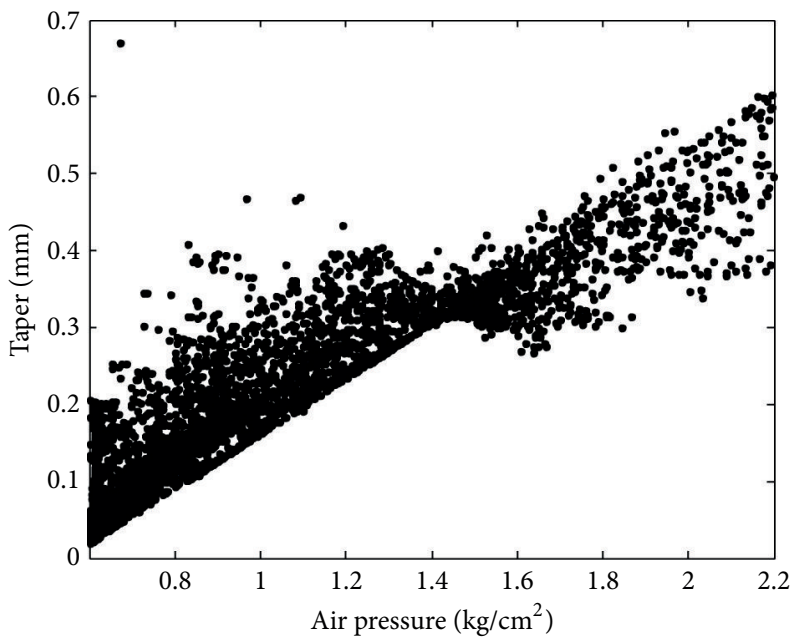

(c)

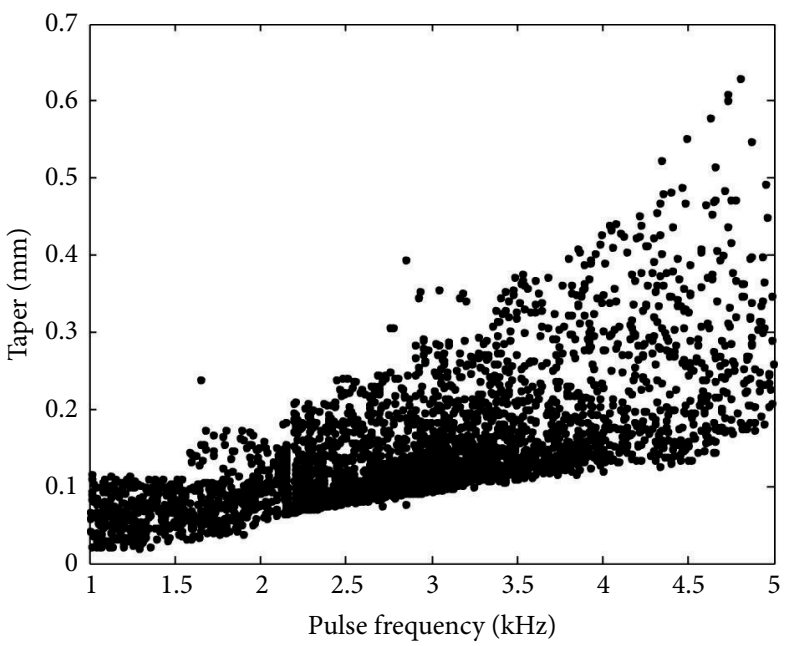

(b)

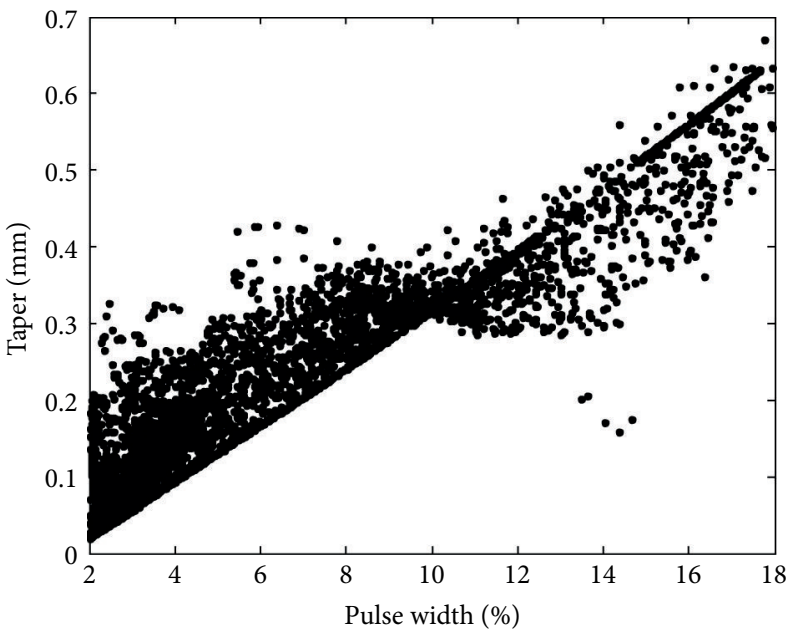

(d)

FIGURE 3: Variations of taper with various LBM process parameters.

TABLE 6: Results for multi-objective optimization.

\begin{tabular}{|c|c|c|c|c|c|c|c|}
\hline Case & Response & Optimal value & $Z_{1}$ & Lamp current (amp) & $\begin{array}{c}\text { Pulse frequency } \\
(\mathrm{kHz})\end{array}$ & $\begin{array}{c}\text { Air pressure } \\
\left(\mathrm{kg} / \mathrm{cm}^{2}\right)\end{array}$ & Pulse width (\%) \\
\hline Kuar et al. [6] & $\begin{array}{l}\text { HAZ } \\
\text { Taper }\end{array}$ & $\begin{array}{l}0.1296 \\
0.0400\end{array}$ & 0.0848 & 17 & 1.62 & 1.04 & 2 \\
\hline Case $1\left(w_{1}=0.5\right.$ and $\left.w_{2}=0.5\right)$ & $\begin{array}{l}\text { HAZ } \\
\text { Taper }\end{array}$ & $\begin{array}{l}0.1019 \\
0.0248\end{array}$ & 0.0634 & 17.18 & 1.5 & 1.33 & 2 \\
\hline Case $2\left(w_{1}=0.9\right.$ and $\left.w_{2}=0.1\right)$ & $\begin{array}{l}\text { HAZ } \\
\text { Taper }\end{array}$ & $\begin{array}{l}0.0281 \\
0.3733\end{array}$ & 0.2007 & 17.2 & 1.5 & 2.16 & 2 \\
\hline Case $3\left(w_{1}=0.1\right.$ and $\left.w_{2}=0.9\right)$ & $\begin{array}{l}\text { HAZ } \\
\text { Taper }\end{array}$ & $\begin{array}{l}0.3124 \\
0.0329\end{array}$ & 0.1891 & 18.66 & 1.34 & 1.20 & 7.95 \\
\hline
\end{tabular}

TABLE 7: Multi-objective optimization performance.

\begin{tabular}{|c|c|c|c|c|}
\hline Case & $Z_{1}$ & Mean & Standard deviation & Standard error \\
\hline Case $1\left(w_{1}=0.5\right.$ and $\left.w_{2}=0.5\right)$ & 0.0634 & 0.0854 & 0.0151 & 0.0048 \\
\hline Case $2\left(w_{1}=0.9\right.$ and $\left.w_{2}=0.1\right)$ & 0.2007 & 0.2532 & 0.0413 & 0.0130 \\
\hline Case $3\left(w_{1}=0.1\right.$ and $\left.w_{2}=0.9\right)$ & 0.1891 & 0.2196 & 0.0309 & 0.0098 \\
\hline
\end{tabular}


TABLE 8: LBM process parameters with their levels.

\begin{tabular}{lccccc}
\hline \multirow{2}{*}{ Parameter } & \multicolumn{5}{c}{ Levels } \\
& -2 & -1 & 0 & 1 & 2 \\
\hline Air pressure $\left(x_{1}\right)\left(\mathrm{kg} / \mathrm{cm}^{2}\right)$ & 0.3 & 0.8 & 1.3 & 1.8 & 2.3 \\
Lamp current $\left(x_{2}\right)(\mathrm{A})$ & 13 & 16 & 19 & 22 & 25 \\
Pulse frequency $\left(x_{3}\right)(\mathrm{kHz})$ & 1 & 2 & 3 & 4 & 5 \\
Pulse width $\left(x_{4}\right)(\%)$ & 2 & 4 & 6 & 8 & 10 \\
Cutting speed $\left(x_{5}\right)(\mathrm{rpm})$ & 7 & 12 & 17 & 22 & 27 \\
\hline
\end{tabular}

3.2. Example 2. Using an Nd:YAG laser-turning system, Dhupal et al. [10] performed micro-grooving operation on cylindrical $\mathrm{Al}_{2} \mathrm{O}_{3}$ workpiece $(10 \mathrm{~mm}$ diameter and $40 \mathrm{~mm}$ length) and also investigated the effects of five process parameters (air pressure, lamp current, pulse frequency, pulse width, and cutting speed) on the upper deviation $\left(Y_{\mathrm{uw}}\right)$, lower deviation $\left(Y_{\mathrm{lw}}\right)$, and depth deviation $\left(Y_{d}\right)$ of the machined micro-groove. Each of the five process parameters was set at five different levels, as shown in Table 8.

Dhupal et al. [10] conducted experiments based on a central composite rotatable second-order design plan and developed the following RSM-based equations for the considered three responses:

$$
\begin{aligned}
Y_{u}(\mathrm{uw})= & -0.00376-0.01690 x_{1}-0.00251 x_{2} \\
& -0.00288 x_{3}+0.00048 x_{4}+0.00185 x_{5} \\
& +0.00678 x_{1}^{2}+0.00232 x_{2}^{2}+0.00276 x_{3}^{2} \\
& -0.00012 x_{4}^{2}+0.00207 x_{5}^{2}+0.00004 x_{1} x_{2} \\
& -0.00134 x_{1} x_{3}+0.00188 x_{1} x_{4}-0.00225 x_{1} x_{5} \\
& -0.00149 x_{2} x_{3}-0.00081 x_{2} x_{4}-0.00052 x_{2} x_{5} \\
& +0.00114 x_{3} x_{4}-0.00262 x_{3} x_{5}+0.00120 x_{4} x_{5}, \\
Y_{u}(\mathrm{lw})= & 0.01857-0.01330 x_{1}-0.00247 x_{2} \\
& -0.00268 x_{3}+0.00120 x_{4}-0.00391 x_{5} \\
& +0.00299 x_{1}^{2}+0.00224 x_{2}^{2}-0.00137 x_{3}^{2} \\
& -0.00122 x_{4}^{2}+0.00051 x_{5}^{2}+0.00235 x_{1} x_{2} \\
& -0.00122 x_{1} x_{3}-0.00168 x_{1} x_{4}+0.00197 x_{1} x_{5} \\
& -0.00197 x_{2} x_{3}-0.00175 x_{2} x_{4}+0.00166 x_{2} x_{5} \\
& -0.0078 x_{3} x_{4}-0.00211 x_{3} x_{5}+0.00378 x_{4} x_{5}, \\
Y_{u}(d)= & 0.01265-0.02510 x_{1}-0.00263 x_{2} \\
& +0.00451 x_{3}+0.00479 x_{4}-0.00229 x_{5} \\
& +0.00338 x_{1}^{2}+0.00383 x_{2}^{2}+0.00168 x_{3}^{2} \\
& +0.00157 x_{4}^{2}-0.00112 x_{5}^{2}-0.00214 x_{1} x_{2} \\
& -0.00472 x_{1} x_{3}-0.00264 x_{1} x_{4}+0.00260 x_{1} x_{5} \\
& -0.00035 x_{2} x_{3}-0.00314 x_{2} x_{4}-0.00365 x_{2} x_{5} \\
& -0.00425 x_{3} x_{4}+0.00006 x_{3} x_{5}+0.00393 x_{4} x_{5} .
\end{aligned}
$$

3.2.1. Single Objective Optimization. The three abovementioned RSM-based second-order equations for the responses are now optimized using $\mathrm{ABC}$ algorithm while treating the responses separately. The constraints are set as $0.3 \leq x_{1} \leq 2.3,13 \leq x_{2} \leq 25,1 \leq x_{3} \leq 5,2 \leq x_{4} \leq 10$, and 7

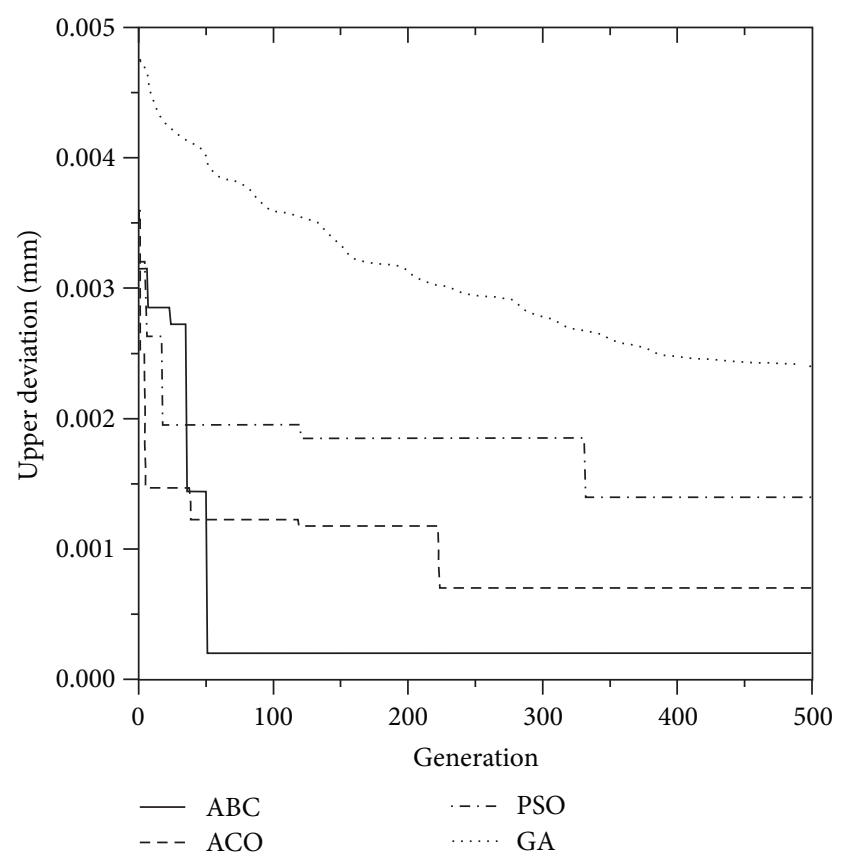

FIgURE 4: Convergence of ABC, ACO, PSO, and GA algorithms for upper deviation.

$\leq x_{5} \leq 27$. The results of this single objective optimization of the responses are given in Table 9. In this case, all the three responses need to be minimized. It is observed from Table 9 that the minimum values for all the three responses are obtained when $\mathrm{ABC}$ algorithm is employed as the optimization tool. The performance of $\mathrm{ABC}$ algorithm is also better than the other population-based optimization methods, as shown in Table 9. Here, it is not possible to compare the results obtained using $\mathrm{ABC}$ algorithm with those of Dhupal et al. [10] as they did not consider the single objective optimization of Nd:YAG laser-turning process. The convergences of ABC, ACO, PSO, and GA algorithms for upper deviation of the machined micro-groove are shown in Figure 4. Table 10 compares the single objective optimization performance of the considered algorithms which again proves the superiority of $\mathrm{ABC}$ algorithm over the others.

The variations of upper deviation with respect to air pressure, lamp current, pulse frequency, pulse width, and cutting speed are exhibited in Figure 5. The dimensional upper deviation from the target is to be minimized. Dhupal et al. [10] observed that the upper deviation becomes lower with increasing values of lamp current and pulse frequency. As the lamp current increases, the laser beam energy increases and the top surface of the work material melts at a faster rate. High-energy laser beam produces low upper deviation because it removes material from the top surface and penetrates at a faster rate into the material to obtain the desired depth. It has also been observed that the change in upper deviation with pulse frequency is less compared to that of lamp current. The pulse width has moderate effect on upper deviation as compared with lamp current. At low pulse width, the upper deviation of the micro-groove approaches to zero, 


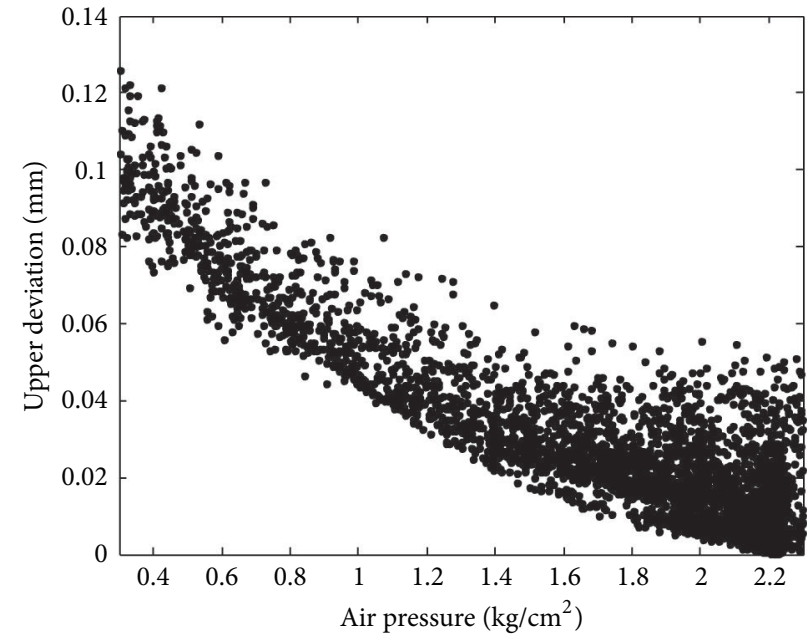

(a)

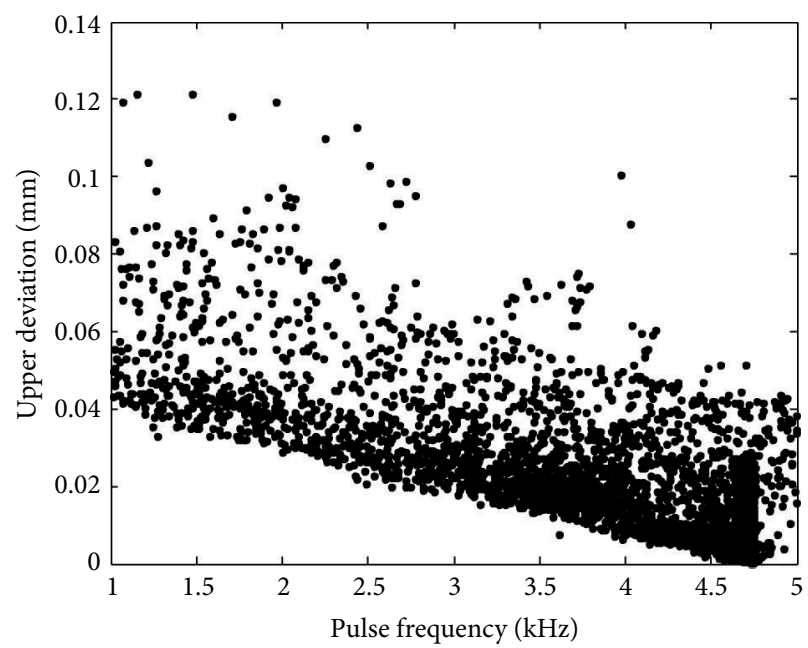

(c)

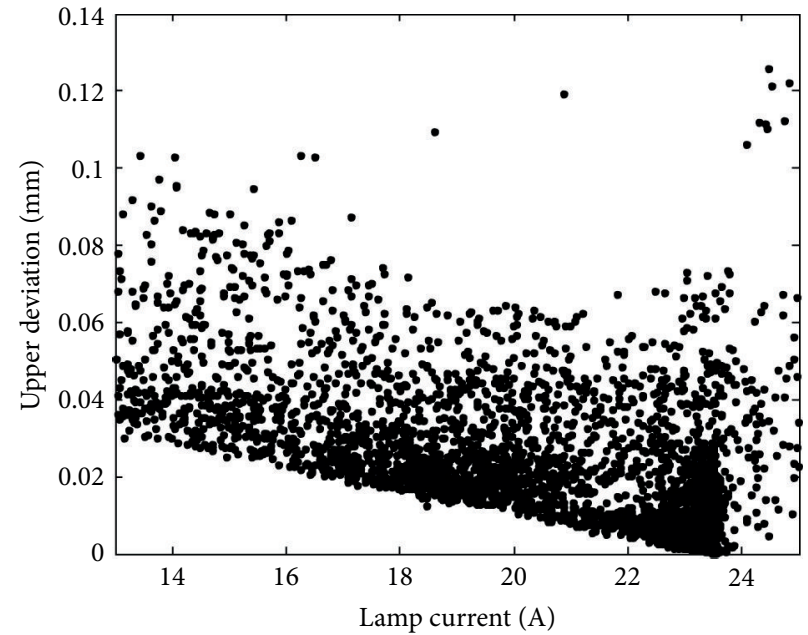

(b)

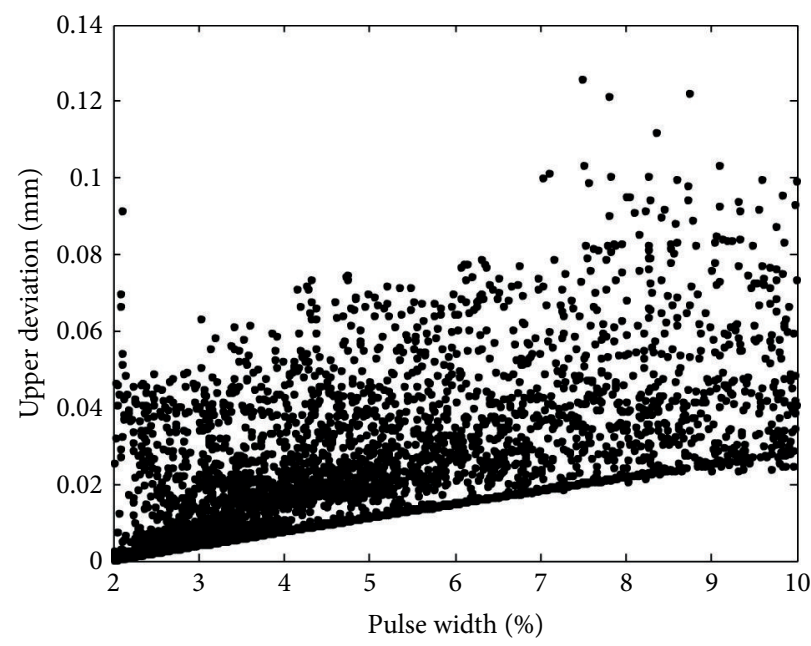

(d)

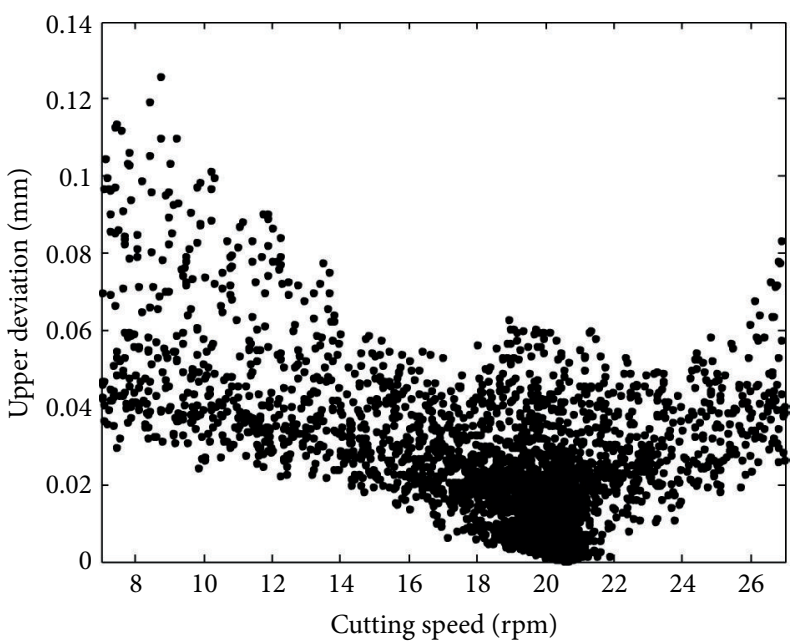

(e)

FIGURE 5: Variations of upper deviation with various LBM process parameters. 


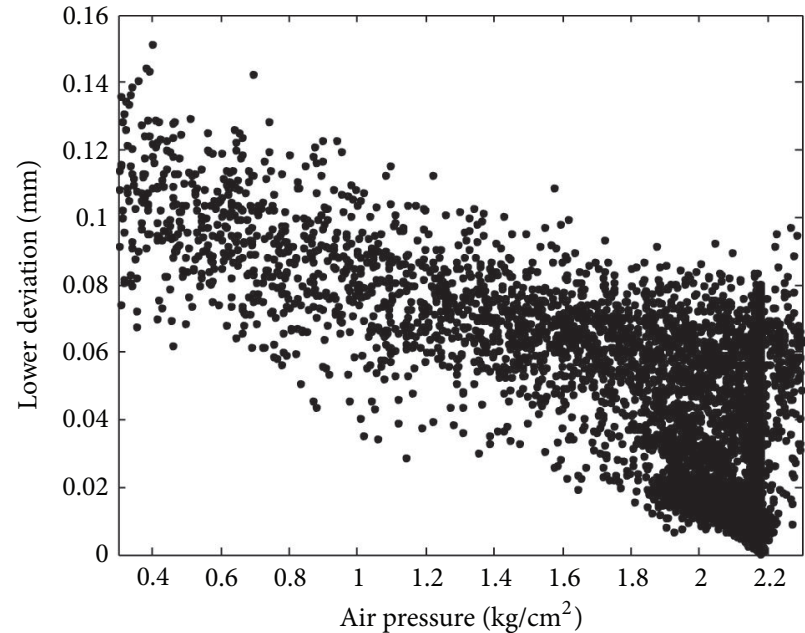

(a)

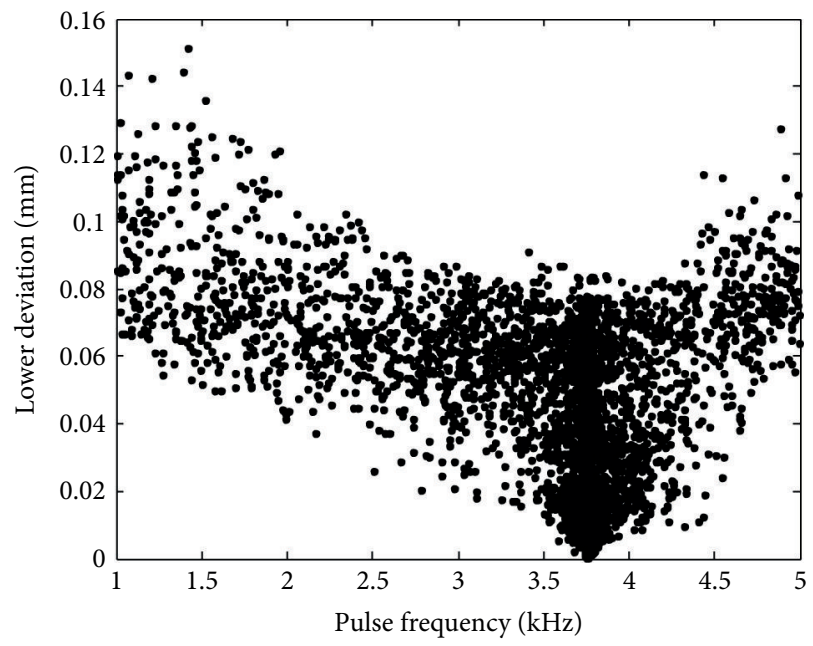

(c)

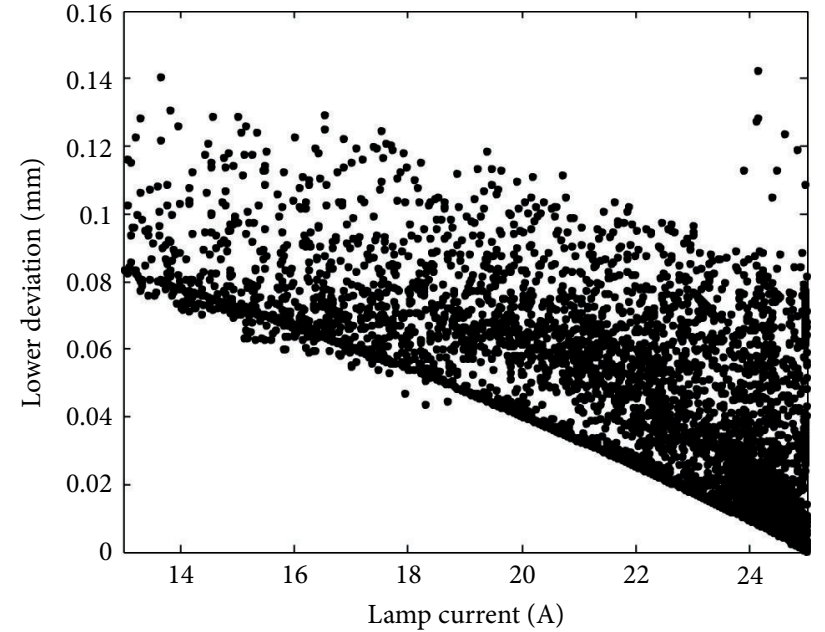

(b)

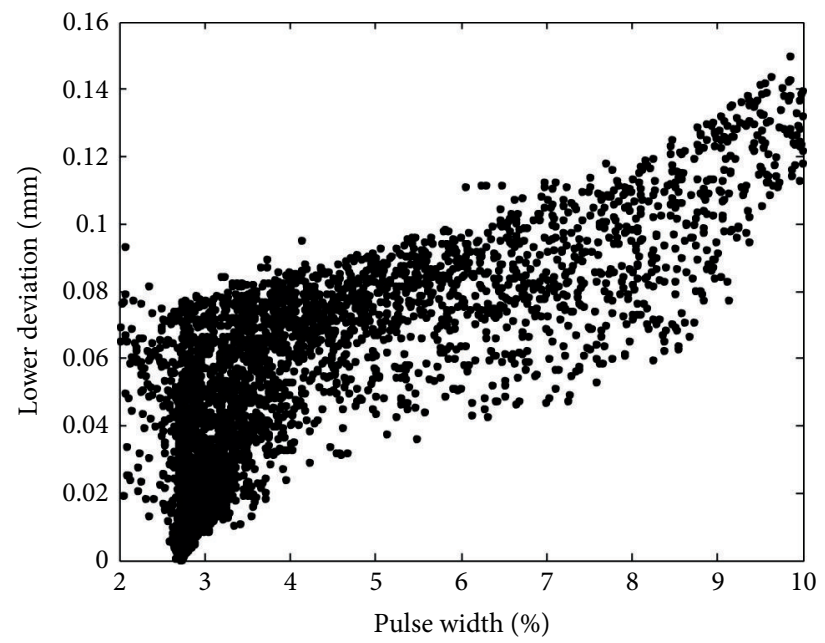

(d)

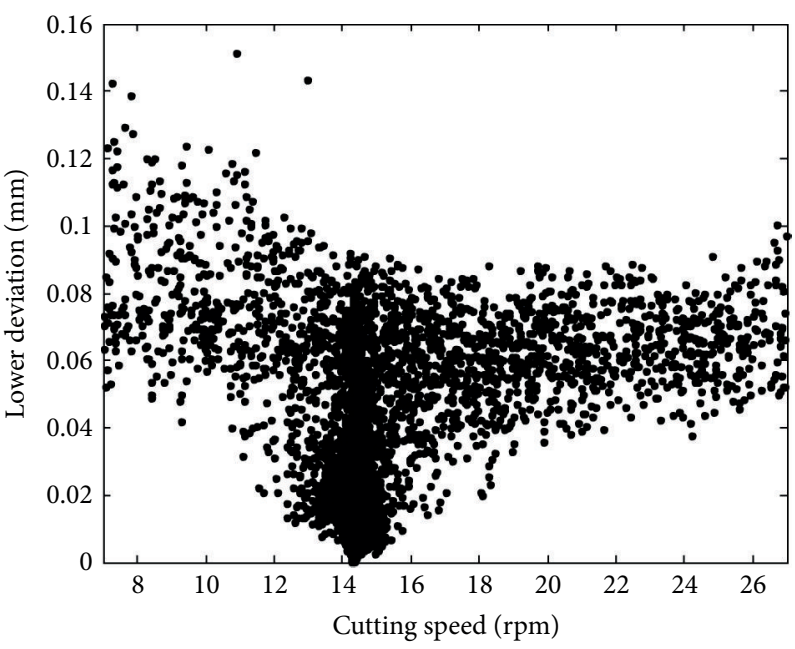

(e)

FIGURE 6: Variations of lower deviation with various LBM process parameters. 


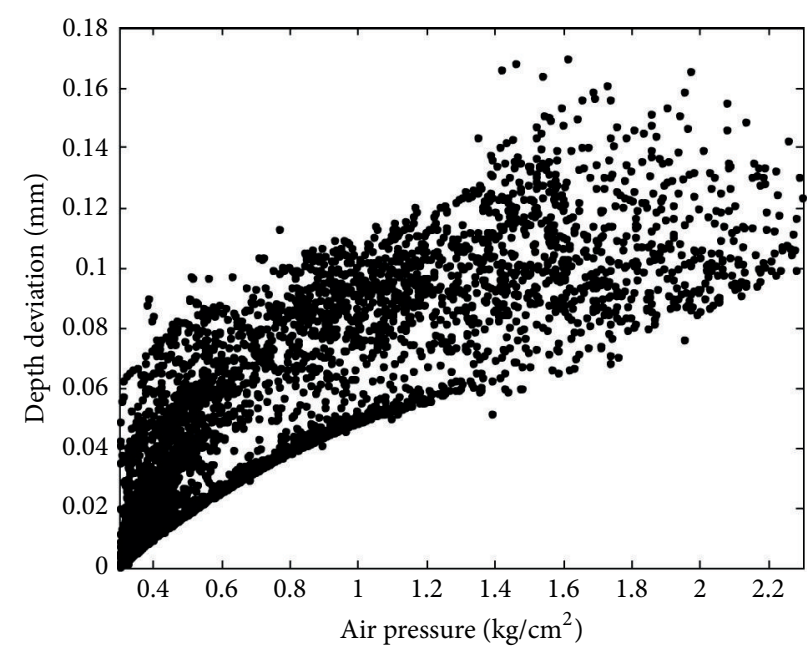

(a)

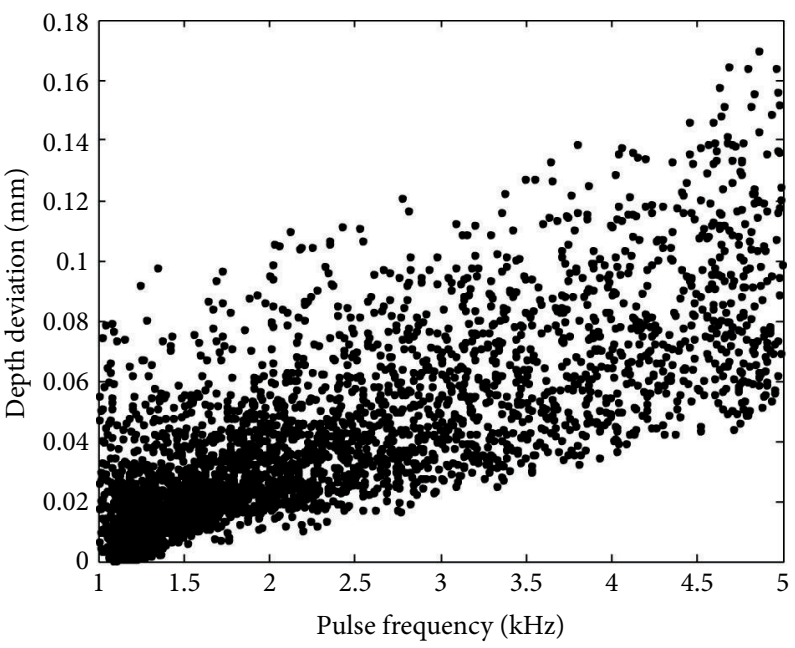

(c)

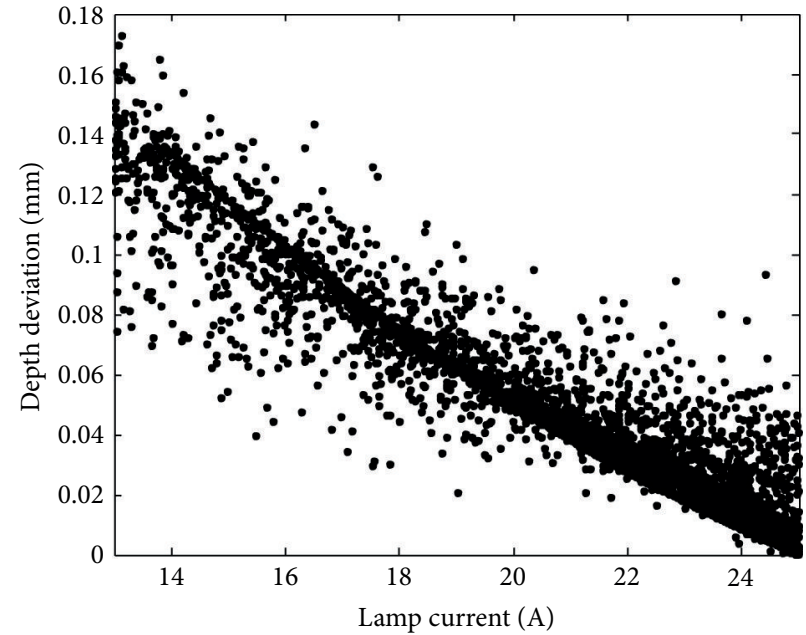

(b)

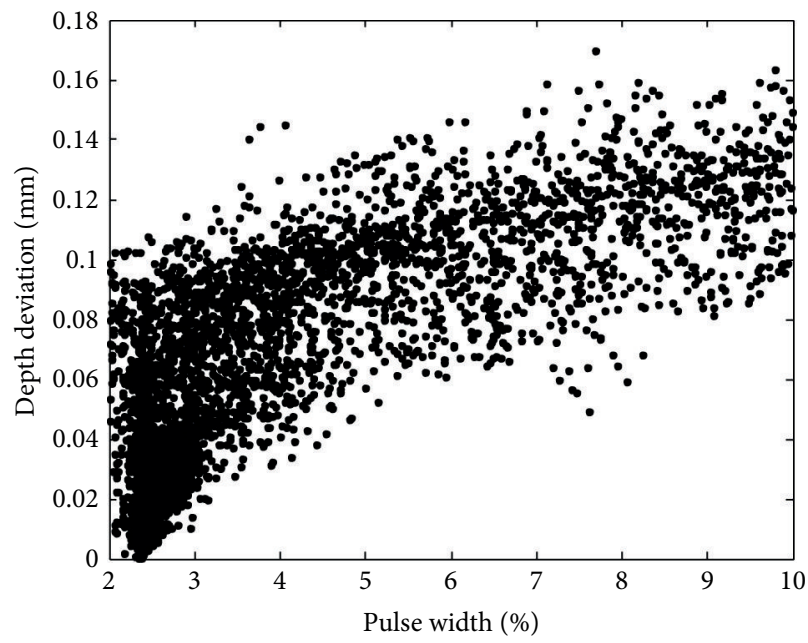

(d)

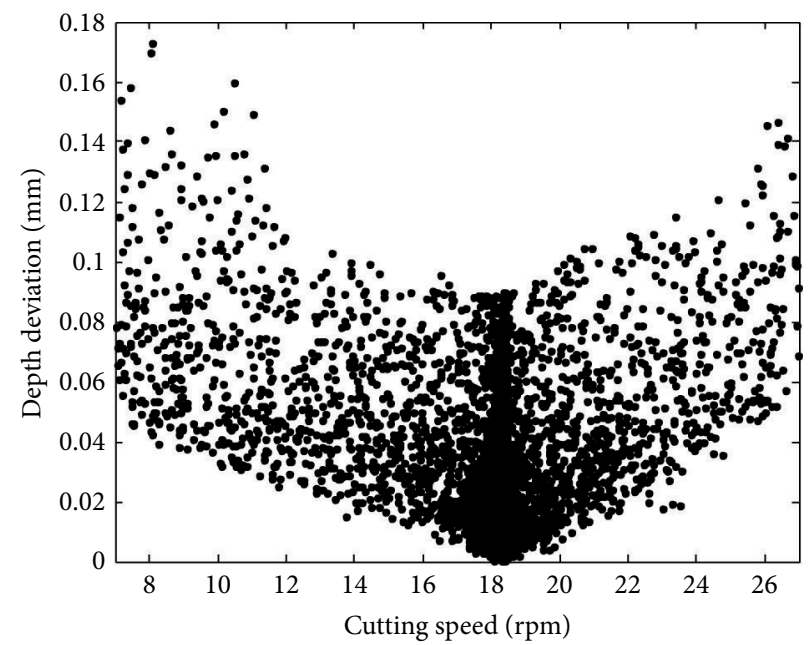

(e)

FIGURE 7: Variations of depth deviation with five LBM process parameters. 
TABLE 9: Single objective optimization results.

\begin{tabular}{|c|c|c|c|c|c|c|c|}
\hline $\begin{array}{l}\text { Optimization } \\
\text { method }\end{array}$ & Response & Optimal value & $\begin{array}{c}\text { Air pressure } \\
\left(\mathrm{kg} / \mathrm{cm}^{2}\right)\end{array}$ & $\begin{array}{c}\text { Lamp current } \\
\text { (amp) }\end{array}$ & $\begin{array}{c}\text { Pulse frequency } \\
(\mathrm{kHz})\end{array}$ & Pulse width (\%) & $\begin{array}{c}\text { Cutting speed } \\
(\mathrm{rpm})\end{array}$ \\
\hline \multirow{3}{*}{ GA } & $Y_{\mathrm{uw}}$ & 0.0024 & 1.73 & 18.25 & 1.39 & 3.62 & 21.48 \\
\hline & $Y_{\mathrm{lw}}$ & 0.0038 & 2.22 & 16.89 & 4.57 & 5.15 & 15.28 \\
\hline & $Y_{d}$ & 0.0037 & 1.68 & 23.50 & 1.75 & 7.60 & 17.25 \\
\hline \multirow{3}{*}{$\begin{array}{l}\text { PSO } \\
\text { algorithm }\end{array}$} & $Y_{\mathrm{uw}}$ & 0.0014 & 1.73 & 14.85 & 2.78 & 9.35 & 17.79 \\
\hline & $Y_{\mathrm{lw}}$ & 0.0024 & 2.18 & 21.61 & 4.17 & 5.04 & 17.21 \\
\hline & $Y_{d}$ & 0.0022 & 1.93 & 17.20 & 4.00 & 8.40 & 24.50 \\
\hline \multirow{3}{*}{$\begin{array}{l}\text { ACO } \\
\text { algorithm }\end{array}$} & $Y_{\mathrm{uw}}$ & 0.0007 & 1.70 & 19.51 & 1.74 & 8.11 & 19.45 \\
\hline & $Y_{1 \mathrm{w}}$ & 0.0008 & 2.22 & 21.91 & 4.27 & 4.64 & 25.19 \\
\hline & $Y_{d}$ & 0.0006 & 1.85 & 20.20 & 2.67 & 9.26 & 23.00 \\
\hline \multirow{3}{*}{$\begin{array}{l}\text { ABC } \\
\text { algorithm }\end{array}$} & $Y_{\mathrm{uw}}$ & 0.0002 & 2.22 & 23.56 & 4.74 & 2.00 & 20.54 \\
\hline & $Y_{\mathrm{lw}}$ & 0.0003 & 2.20 & 25.00 & 3.75 & 2.72 & 14.25 \\
\hline & $Y_{d}$ & 0.0003 & 0.30 & 25.00 & 1.10 & 2.35 & 18.30 \\
\hline
\end{tabular}

TABLE 10: Single objective optimization performance.

\begin{tabular}{lccccc}
\hline Optimization method & Response & Optimal value & Mean & Standard deviation & Standard error \\
\hline \multirow{3}{*}{ GA } & $Y_{\text {uw }}$ & 0.0024 & 0.0033 & 0.00067 & 0.00021 \\
& $Y_{\text {lw }}$ & 0.0038 & 0.0049 & 0.00083 & 0.00026 \\
\hline \multirow{3}{*}{ PSO algorithm } & $Y_{d}$ & 0.0037 & 0.0049 & 0.00073 & 0.00031 \\
& $Y_{\text {uw }}$ & 0.0014 & 0.0025 & 0.00060 & 0.00023 \\
& $Y_{\text {lw }}$ & 0.0024 & 0.0032 & 0.00057 & 0.00019 \\
ACO algorithm & $Y_{d}$ & 0.0022 & 0.0029 & 0.00049 & 0.00059 \\
& $Y_{\text {uw }}$ & 0.0007 & 0.0014 & 0.00071 & 0.00019 \\
\hline \multirow{3}{*}{ ABC algorithm } & $Y_{\text {lw }}$ & 0.0008 & 0.0017 & 0.00046 & 0.00022 \\
& $Y_{d}$ & 0.0006 & 0.0015 & 0.00048 & 0.00014 \\
& $Y_{\text {uw }}$ & 0.0002 & 0.0008 & 0.0015 & 0.00013 \\
\hline
\end{tabular}

and the desired value of upper deviation can be achieved while performing laser turning operation at lower pulse width. Then, the upper deviation increases with increase in pulse width. Higher air pressure has been recommended for higher dimensional accuracy in the form of upper deviation. It has been found that at low cutting speed of the workpiece, the upper deviation becomes less. At low cutting speed, the material of the workpiece absorbs sufficient amount of heat energy for longer time, and as a result, the material is removed from the upper surface to obtain the required upper deviation. At high cutting speed, the ablation rate of material from the upper surface is higher, and as a result, the upper deviation becomes high. These findings of Dhupal et al. [10] exactly match with those observed in Figure 5.

The variations of lower deviation of the micro-groove with respect to five Nd:YAG laser-turning process parameters are exhibited in Figure 6. It is observed that with the increase in the values of air pressure and lamp current, the lower deviation decreases, and it increases with the increasing value of pulse width. The effects of pulse frequency and cutting speed on lower deviation are almost nonlinear. On the other hand, Figure 7 shows the effects of five machining parameters on depth deviation of the microgroove. Depth deviation almost linearly increases with the gradual increment in the values of air pressure, pulse frequency, and pulse width, whereas minimum depth deviation is achieved at higher values of lamp current. Cutting speed has a nonlinear effect on depth deviation. Dhupal et al. [10] extensively studied and analyzed the influences of the five process parameters on lower deviation and depth deviation of the machined microgroove.

3.2.2. Multiobjective Optimization. The same optimization problem is now solved using ABC algorithm while giving equal weights to all the three responses. For this multiobjective optimization problem, the following objective function is developed and solved with respect to the constraints as imposed in the case of single objective optimization as

$$
\operatorname{Min}\left(Z_{2}\right)=\frac{0.33 Y_{u}(\mathrm{uw})}{\mathrm{uw}_{\min }}+\frac{0.33 Y_{u}(\mathrm{lw})}{\mathrm{lw}_{\min }}+\frac{0.33 Y_{u}(d)}{d_{\min }}
$$

where $Y_{u}(\mathrm{uw}), Y_{u}(\mathrm{lw})$, and $Y_{u}(d)$ are the second-order RSMbased equations for upper deviation, lower deviation, and depth deviation respectively; $\mathrm{uw}_{\min }, \mathrm{lw}_{\min }$, and $d_{\min }$ are the minimum values of upper deviation, lower deviation and depth deviation, respectively. These minimum values are obtained from the results of single objective optimization. The multi-objective optimization results are shown in Table 11. Dhupal et al. [10] applied desirability function 
TABLE 11: Multi-objective optimization results.

\begin{tabular}{|c|c|c|c|c|c|c|c|}
\hline $\begin{array}{l}\text { Optimization } \\
\text { method }\end{array}$ & Response & Optimal value & $\begin{array}{c}\text { Air pressure } \\
\left(\mathrm{kg} / \mathrm{cm}^{2}\right)\end{array}$ & $\begin{array}{c}\text { Lamp current } \\
\text { (amp) }\end{array}$ & $\begin{array}{c}\text { Pulse frequency } \\
(\mathrm{kHz})\end{array}$ & Pulse width (\%) & $\begin{array}{c}\text { Cutting speed } \\
(\mathrm{rpm})\end{array}$ \\
\hline \multirow{3}{*}{$\begin{array}{l}\text { Dhupal et al. } \\
{[10]}\end{array}$} & $Y_{\mathrm{uw}}$ & -0.0001 & \multirow{3}{*}{0.93} & \multirow{3}{*}{22.51} & \multirow{3}{*}{1.48} & \multirow{3}{*}{2.39} & \multirow{3}{*}{10.43} \\
\hline & $Y_{\mathrm{lw}}$ & -0.0002 & & & & & \\
\hline & $Y_{d}$ & -0.0009 & & & & & \\
\hline \multirow{3}{*}{$\begin{array}{l}\text { ABC } \\
\text { algorithm }\end{array}$} & $Y_{\mathrm{uw}}$ & 0.0002 & \multirow{3}{*}{1.64} & \multirow{3}{*}{18.87} & \multirow{3}{*}{3.21} & \multirow{3}{*}{9.80} & \multirow{3}{*}{7.67} \\
\hline & $Y_{\mathrm{lw}}$ & 0.0006 & & & & & \\
\hline & $Y_{d}$ & 0.0003 & & & & & \\
\hline
\end{tabular}

approach to optimize the multiple responses of $\mathrm{Nd}$ :YAG laser-turning process for generation of micro-groove and achieved the optimal values of the responses as negatives which are infeasible to obtain. Applying $\mathrm{ABC}$ algorithm, it is observed that a combination of air pressure $=1.64 \mathrm{~kg} / \mathrm{cm}^{2}$, lamp current $=18.87 \mathrm{amp}$, pulse frequency $=3.21 \mathrm{kHz}$, pulse width $=9.80 \%$, and cutting speed $=7.67 \mathrm{rpm}$ would simultaneously optimize all the three responses of the LBM process. The optimal value of the objective function $\left(Z_{2}\right)$ is determined as 0.000365 .

The $\mathrm{ABC}$ algorithm is based on the foraging behavior of the honey bee colonies. The model consists of three essential components, that is, employed and unemployed foraging bees, and food sources. It also defines two leading modes of behavior which are necessary for self-organizing and collective intelligence, that is, recruitment of foragers to rich food sources resulting in positive feedback and abandonment of poor sources by foragers causing negative feedback.

In $\mathrm{ABC}$ algorithm, a colony of artificial forager bees (agents) search for rich artificial food sources (good solutions for a given problem). To apply ABC algorithm, the considered optimization problem is first converted to the problem of finding the best parameter vector which minimizes the given objective function. Then, the artificial bees randomly discover a population of initial solution vectors and then iteratively improve them by employing the strategy of moving towards better solutions by means of a neighborhood search mechanism while abandoning poor solutions.

The most innovative feature of $\mathrm{ABC}$ algorithm is the concept of exchange of information amongst the onlooker bees to find out a better food source which minimizes the search iteration for the global optimal and avoids candidate solutions which are sub-optimal. The same point is observed inFigure 1 (convergence of ABC, ACO, PSO and GA algorithms for HAZ thickness) and Figure 4 (convergence of ABC, ACO, $\mathrm{PSO}$, and GA algorithms for upper deviation) where it is evident that due to its superior searching methodology, ABC algorithm reaches the convergent solution much earlier than ACO, PSO, and GA.

\section{Conclusions}

In this paper, the parametric optimization problems for two Nd:YAG laser beam machining processes are solved applying ABC algorithm. For both the cases, the results of single as well as multi-objective optimization of the LBM process are derived. It is observed that the optimal values of the responses derived by $\mathrm{ABC}$ algorithm are far better than those obtained by the past researchers. The comparison of the performance of $\mathrm{ABC}$ algorithm with other populationbased algorithms proves its superiority and applicability as an effective optimization tool. The optimal response values obtained using $\mathrm{ABC}$ algorithm have minimum dispersion and are close to the target solutions. Although $\mathrm{ABC}$ algorithm gives excellent results, its CPU time is quite comparable with that of the other optimization algorithms. The results of two sample paired $t$-tests also demonstrate its superiority over the other considered algorithms. It is also observed that for multi-objective optimization, it is always preferable to assign equal importance to all the considered responses. The derived parametric combinations for Nd:YAG LBM process would now help the process engineers to set the operating levels of various process parameters at their optimal values to have enhanced machining performance. This algorithm may also be effectively applied for parametric optimization of other machining processes.

\section{References}

[1] V. K. Jain, Advanced Machining Processes, Allied Publishers Pvt. Limited, New Delhi, India, 2005.

[2] J. Meijer, "Laser beam machining (LBM), state of the art and new opportunities," Journal of Materials Processing Technology, vol. 149, no. 1-3, pp. 2-17, 2004.

[3] A. K. Dubey and V. Yadava, "Laser beam machining: a review," International Journal of Machine Tools and Manufacture, vol. 48, no. 6, pp. 609-628, 2008.

[4] A. K. Dubey and V. Yadava, "Experimental study of Nd:YAG laser beam machining: an overview," Journal of Materials Processing Technology, vol. 195, no. 1-3, pp. 15-26, 2008.

[5] J. Mathew, G. L. Goswami, N. Ramakrishnan, and N. K. Naik, "Parametric studies on pulsed Nd:YAG laser cutting of carbon fibre reinforced plastic composites," Journal of Materials Processing Technology, vol. 89-90, pp. 198-203, 1999.

[6] A. S. Kuar, B. Doloi, and B. Bhattacharyya, "Modelling and analysis of pulsed Nd:YAG laser machining characteristics during micro-drilling of zirconia $\left(\mathrm{ZrO}_{2}\right)$," International Journal of Machine Tools and Manufacture, vol. 46, no. 12-13, pp. 13011310, 2006.

[7] A. S. Kuar, G. Paul, and S. Mitra, "Nd:YAG laser micromachining of alumina-aluminium interpenetrating phase composite using response surface methodology," International Journal of 
Machining and Machinability of Materials, vol. 1, pp. 432-444, 2006.

[8] D. Dhupal, B. Doloi, and B. Bhattacharyya, "Optimization of process parameters of Nd:YAG laser microgrooving of $\mathrm{Al}_{2} \mathrm{TiO}_{5}$ ceramic material by response surface methodology and artificial neural network algorithm," Proceedings of the Institution of Mechanical Engineers B, vol. 221, no. 8, pp. 1341-1351, 2007.

[9] A. K. Dubey and V. Yadava, "Multi-objective optimisation of laser beam cutting process," Optics and Laser Technology, vol. 40, no. 3, pp. 562-570, 2008.

[10] D. Dhupal, B. Doloi, and B. Bhattacharyya, "Pulsed Nd:YAG laser turning of micro-groove on aluminum oxide ceramic $\left(\mathrm{Al}_{2} \mathrm{O}_{3}\right)$," International Journal of Machine Tools and Manufacture, vol. 48, no. 2, pp. 236-248, 2008.

[11] A. K. Dubey and V. Yadava, "Optimization of kerf quality during pulsed laser cutting of aluminium alloy sheet," Journal of Materials Processing Technology, vol. 204, no. 1-3, pp. 412-418, 2008.

[12] D. Dhupal, B. Doloi, and B. Bhattacharyya, "Parametric analysis and optimization of Nd:YAG laser micro-grooving of aluminum titanate $\left(\mathrm{Al}_{2} \mathrm{TiO}_{5}\right)$ ceramics," International Journal of Advanced Manufacturing Technology, vol. 36, no. 9-10, pp. 883$893,2008$.

[13] U. Çaydaş and A. Hasçalık, "Use of the grey relational analysis to determine optimum laser cutting parameters with multiperformance characteristics," Optics \& Laser Technology, vol. 40, pp. 987-994, 2008.

[14] D. Dhupal, B. Doloi, and B. Bhattacharyya, "Modeling and optimization on Nd:YAG laser turned micro-grooving of cylindrical ceramic material," Optics and Lasers in Engineering, vol. 47, no. 9, pp. 917-925, 2009.

[15] R. Rao and V. Yadava, "Multi-objective optimization of Nd:YAG laser cutting of thin superalloy sheet using grey relational analysis with entropy measurement," Optics and Laser Technology, vol. 41, no. 8, pp. 922-930, 2009.

[16] J. Ciurana, G. Arias, and T. Ozel, "Neural network modeling and particle swarm optimization (PSO) of process parameters in pulsed laser micromachining of hardened AISI H13 steel," Materials and Manufacturing Processes, vol. 24, no. 3, pp. 358368, 2009.

[17] Sivarao, T. J. S. Anand, and A. Shukor, "RSM based modeling for surface roughness prediction in laser machining," International Journal of Engineering \& Technology, vol. 10, pp. 32-37, 2010.

[18] B. Doloi, D. Dhupal, and B. Bhattacharyya, "Modelling and analysis on machining characteristics during pulsed Nd:YAG laser microgrooving of aluminium titanate $\left(\mathrm{Al}_{2} \mathrm{TiO}_{5}\right)$," International Journal of Manufacturing Technology and Management, vol. 21, no. 1-2, pp. 30-41, 2010.

[19] A. S. Kuar, S. K. Dhara, and S. Mitra, "Multi-response optimisation of Nd:YAG laser micro-machining of die steel using response surface methodology," International Journal of Manufacturing Technology and Management, vol. 21, no. 1-2, pp. 17-29, 2010.

[20] A. Sharma, V. Yadava, and R. Rao, "Optimization of kerf quality characteristics during Nd: YAG laser cutting of nickel based superalloy sheet for straight and curved cut profiles," Optics and Lasers in Engineering, vol. 48, no. 9, pp. 915-925, 2010.

[21] R. Biswas, A. S. Kuar, S. Sarkar, and S. Mitra, "A parametric study of pulsed Nd:YAG laser micro-drilling of gamma-titanium aluminide," Optics and Laser Technology, vol. 42, no. 1, pp. 23-31, 2010.
[22] G. Kibria, B. Doloi, and B. Bhattacharyya, "Experimental analysis on Nd:YAG laser micro-turning of alumina ceramic," International Journal of Advanced Manufacturing Technology, vol. 50, no. 5-8, pp. 643-650, 2010.

[23] R. Biswas, A. S. Kuar, S. K. Biswas, and S. Mitra, "Effects of process parameters on hole circularity and taper in pulsed Nd:YAG laser microdrilling of Tin- $\mathrm{Al}_{2} \mathrm{O}_{3}$ composites," Materials and Manufacturing Processes, vol. 25, no. 6, pp. 503-514, 2010.

[24] R. Biswas, A. S. Kuar, S. K. Biswas, and S. Mitra, "Characterization of hole circularity in pulsed Nd:YAG laser micro-drilling of $\mathrm{TiN}-\mathrm{Al}_{2} \mathrm{O}_{3}$ composites," International Journal of Advanced Manufacturing Technology, vol. 51, no. 9-12, pp. 983-994, 2010.

[25] S. Panda, D. Mishra, and B. B. Biswal, "Determination of optimum parameters with multi-performance characteristics in laser drilling - a grey relational analysis approach," International Journal of Advanced Manufacturing Technology, vol. 54, no. 9-12, pp. 957-967, 2011.

[26] T. V. Sibalija, S. Z. Petronic, V. D. Majstorovic, R. ProkicCvetkovic, and A. Milosavljevic, "Multi-response design of Nd:YAG laser drilling of Ni-based superalloy sheets using Taguchi's quality loss function, multivariate statistical methods and artificial intelligence," International Journal of Advanced Manufacturing Technology, vol. 54, no. 5-8, pp. 537-552, 2011.

[27] D. Karaboga and B. Basturk, "Artificial bee colony (ABC) optimization algorithm for solving constrained optimization problems," in Foundations of Fuzzy Logic and Soft Computing, vol. 4529, pp. 789-798, Springer, Berlin, Germany, 2007.

[28] D. Karaboga and B. Basturk, "A powerful and efficient algorithm for numerical function optimization: artificial bee colony (ABC) algorithm," Journal of Global Optimization, vol. 39, no. 3, pp. 459-471, 2007.

[29] D. Karaboga and B. Basturk, "On the performance of artificial bee colony (ABC) algorithm," Applied Soft Computing, vol. 8, no. 1, pp. 687-697, 2008.

[30] D. Karaboga and B. Akay, "A comparative study of artificial bee colony algorithm," Applied Mathematics and Computation, vol. 214, no. 1, pp. 108-132, 2009.

[31] S. Samanta and S. Chakraborty, "Parametric optimization of some non-traditional machining processes using artificial bee colony algorithm," Engineering Applications of Artificial Intelligence, vol. 24, no. 6, pp. 946-957, 2011.

[32] T. L. Saaty, The Analytic Hierarchy Process, McGraw-Hill, New York, NY, USA, 1980. 

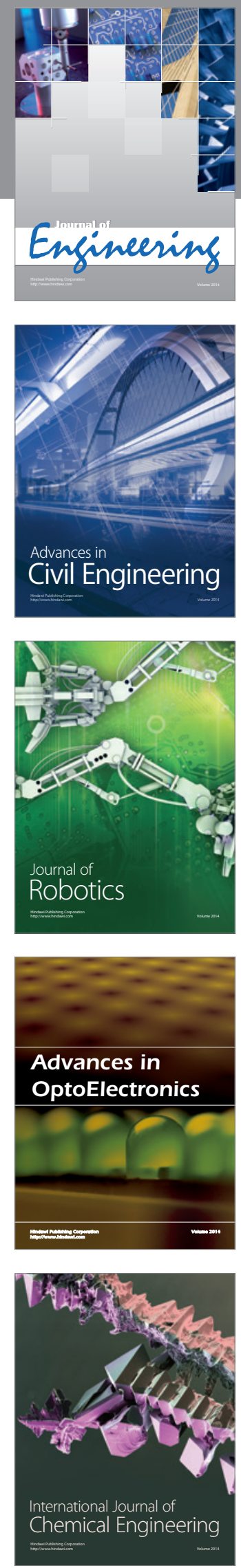

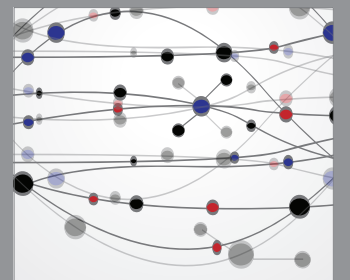

The Scientific World Journal
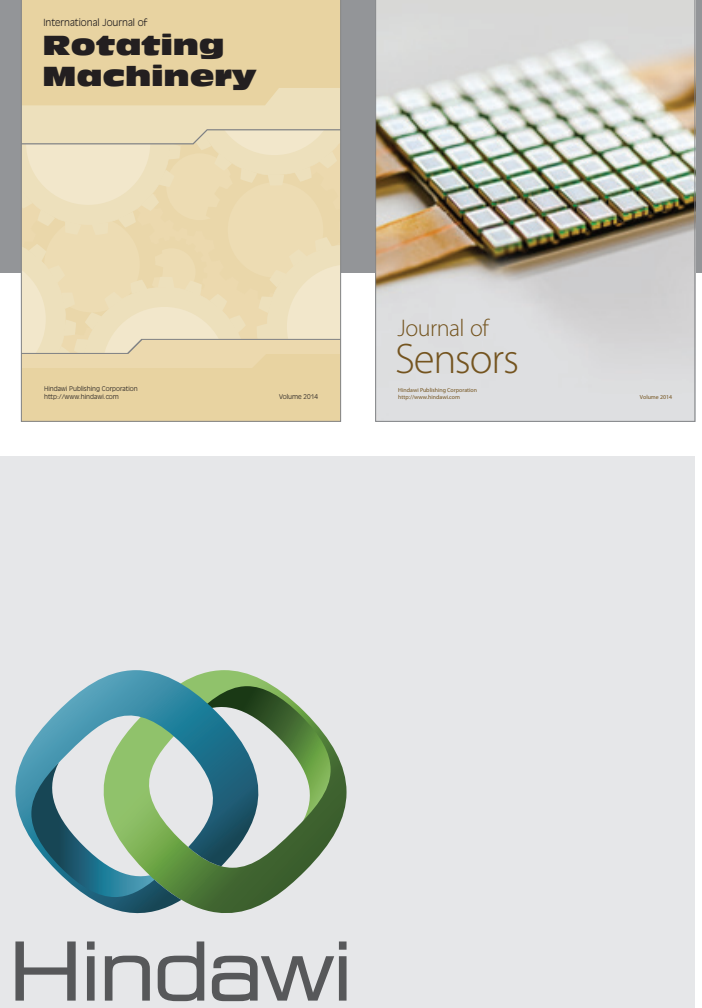

Submit your manuscripts at http://www.hindawi.com
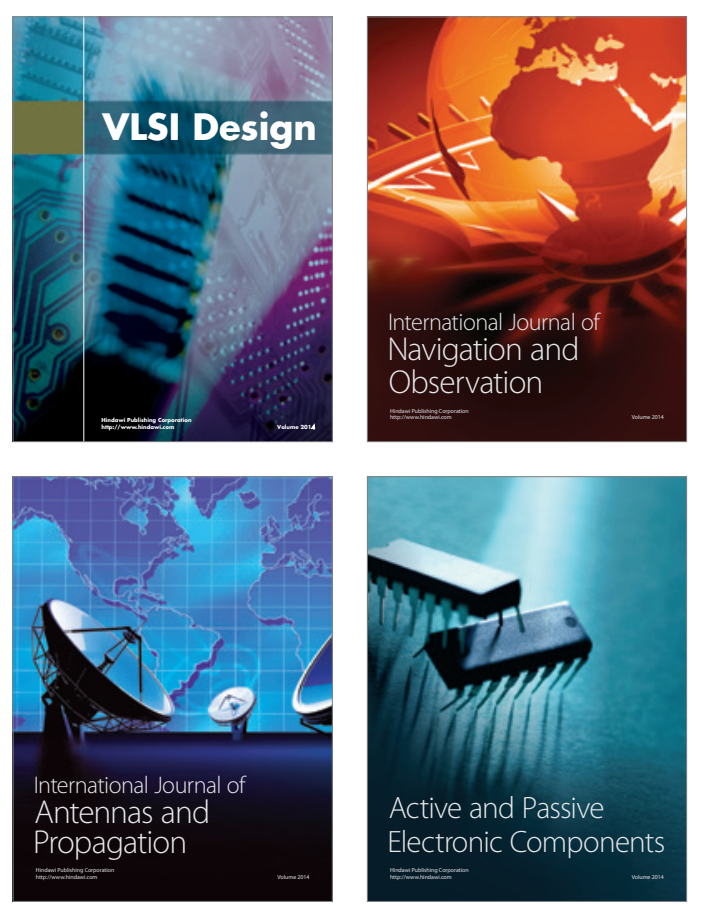
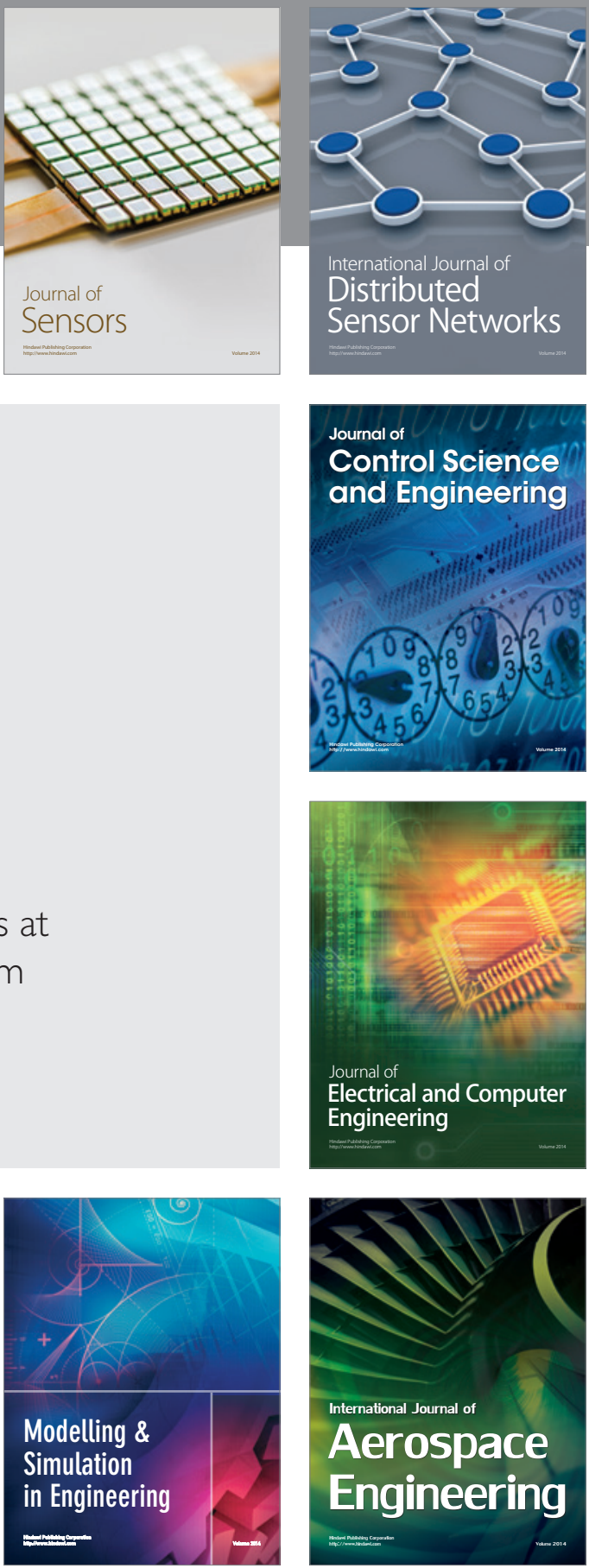

Journal of

Control Science

and Engineering
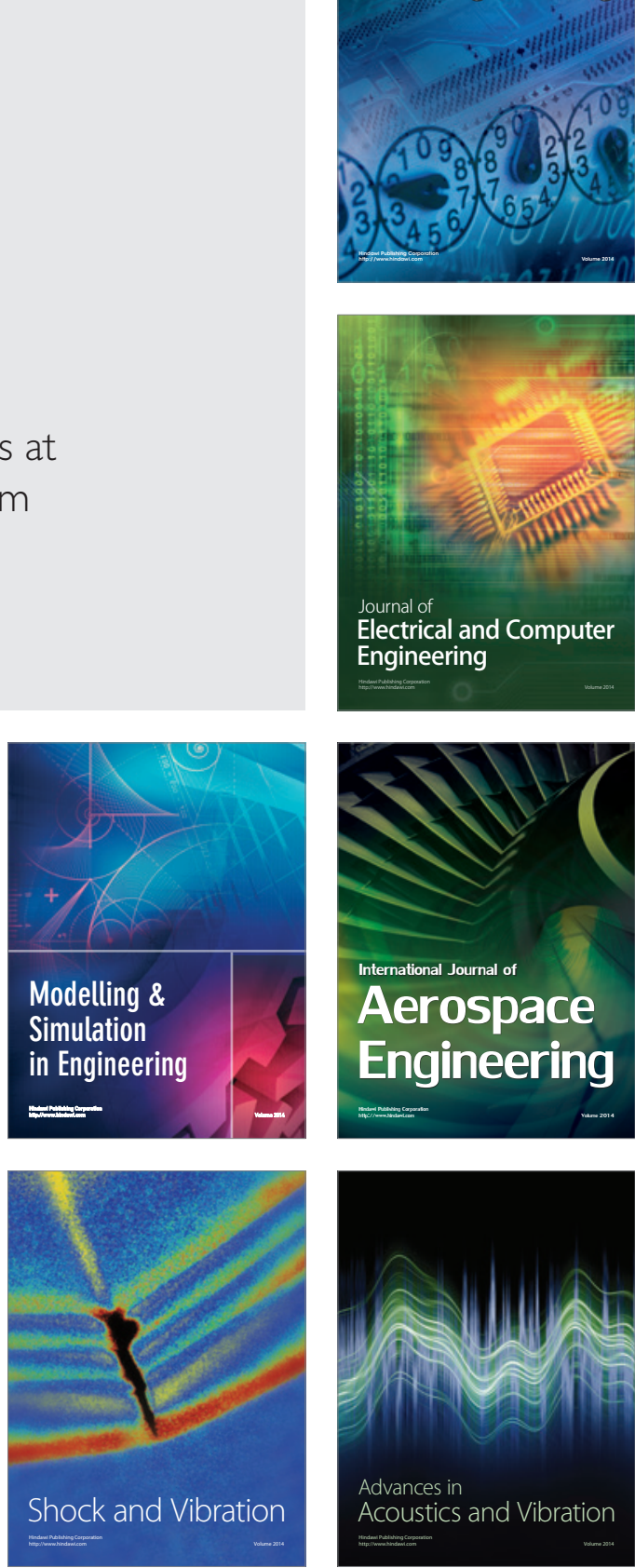